موقف الحكومة التركية من حرب الحكومة التركية من حرب الخليج الأولى الخلى

\title{
1988 - 1980
}

\section{هاى محمود محمد على نايل}

مدرس التاريخ الحديث والمعاصر بالأكاديمية الحديثة محثد

اندلعت حرب الخليج الأولى بين العراق وإيران في 4 سبتمبر 1980 واستمرت

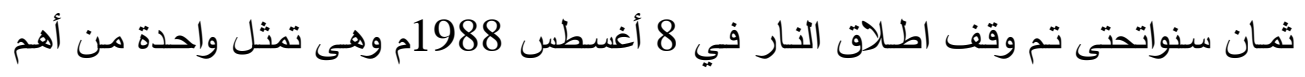

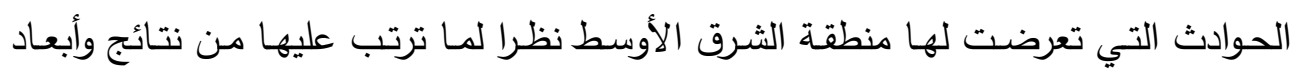
محلية وإقليمية ودولية(1).

وقد كان للمجتمع الدولي مواقف متناقضة إزاء هذه الحرب التي جاءت باءت بعد تاريخ طويل

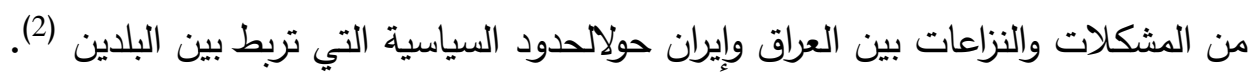

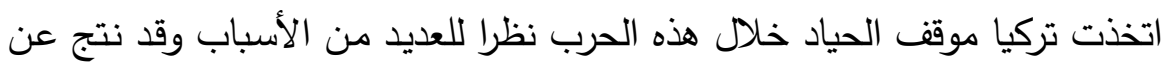

موقفها تحقيق كثير من الدكاسب و من خلال هذا البحث نسعى لرصد ما يلي:-

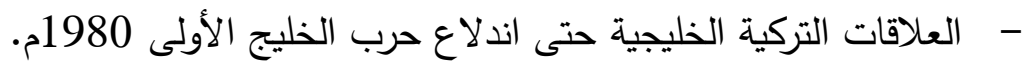
- - تطور علاقة تركيا بالعراق وايران. - - - المشكلات الحدودية العراقية الإيرانية.

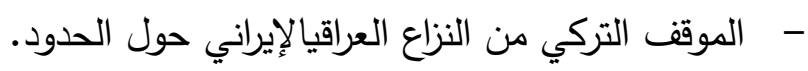

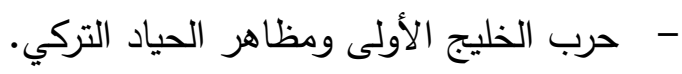

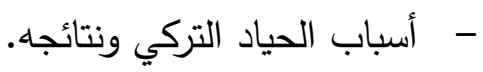




\section{العلاقات التركية الخليجية حتى اندلاع حرب الخليج الأولى 1980م 1980م :}

بدأ اهتمام الدولة العثمانية بالخليج العربي منذ القرن السادس عشر الميلادي بسبب تخوفها من الزحف البرتغالي الذي وصل إلى سواحل الهند 1504 مما دفع الدولة العثانية إلى توجيه جيوشها إلى المنطقة العربية فسيطرت على الموصل والثـام 1516 ثم مصر 1517 حتى دخلت البصرة 1546م وبعدها زحفت إلى الخليج العربي اعتبارا من 1550م حيث فرضت سيطرتها على الإحساء ثم البحرين ومسقط، لكنها عجزت عن السيطرة على سواحل الخليج العربي (3).

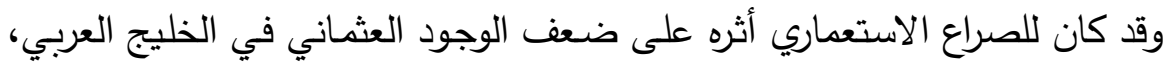
حيث دخلت الدولة العثمانية في صراع ضد البرتغال ثم بريطانيا التي نجحت في إحكام قبضتها على المنطقة فيما بقيا من نفوذ العثماني لا يتجاوز ما وراء الإحساء وبلاد الحجاز

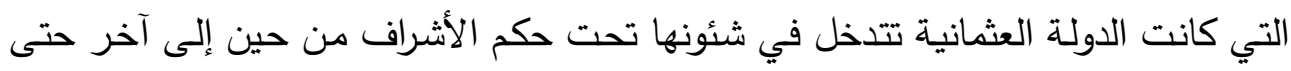

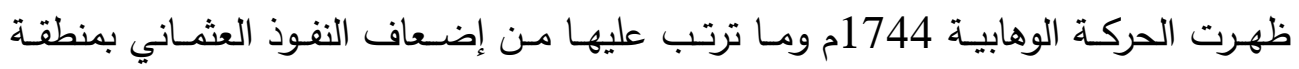
الحجاز حتى استعان السلطان العثماني بجهود محمد على واليه على مصر للقضـاء على هذه الحركة خلال الفترة من 1811-1818م (4).

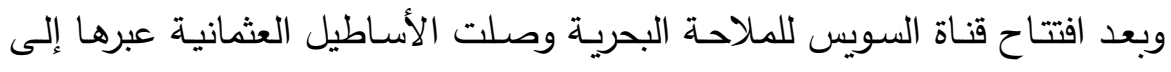
سواحل البحر الأحمر والخليج العربي، وتمكنت الدولة العثمانية عن طريق مدحت باشا واليها على بغداد من فرض السيطرة على الإحساء وقطر، غير أن النفوذ البريطاني الذي اتسع

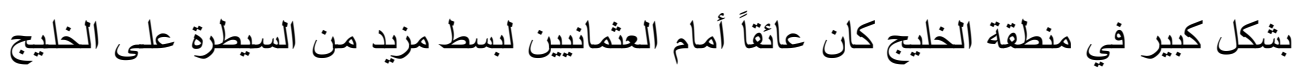
حتى في المناطق التي سيطرو عليها من قبل فضـلاً عن مناوءاتسعود بن فيصل للحاميات

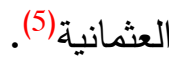

$$
\text { (3) العربية، القاهرة، أعز، ، 1991م، صدصي الدين: العلاقات العربية التركية من منظور عربي، ج3، معهد البحوث و الدراسات }
$$

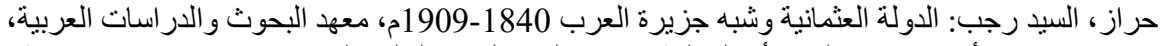

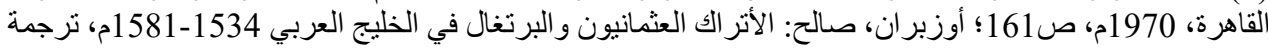

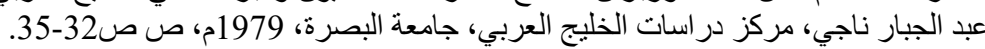
باغي، إسماعيل: سياسة مدحت باثشاً تجاه الخليج العربي، مجلة الوثيقة، العدد (27)، البحرين، 1995م، ص

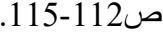


موقف الحكومة التركية من حرب الخليج الأولى لآل

ومن خلال تثجيع العثمانيون لآل الرشيد في حائل على غزو آل سعود بعد وفاة

سعود بن فيصل هُزم آل سعود في القصيم 1890 وتلا ذلك عزو آل الرشيد للكويت 1901

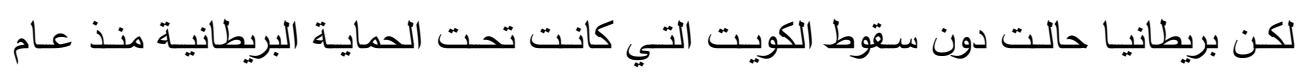
1899م(6). كما نجح عبد العزيز آل سعود في استرداد الرياض بعد انتصاره على آل الرشيد

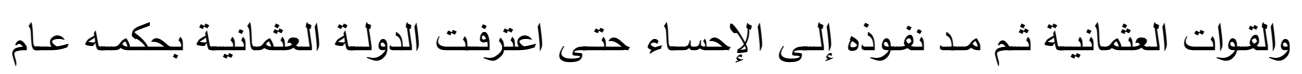
(7) 1913

بعد قيام الحرب العالمية الأولى 1914م قامت بريطانيا باحتلال البصرة ثم فرضت

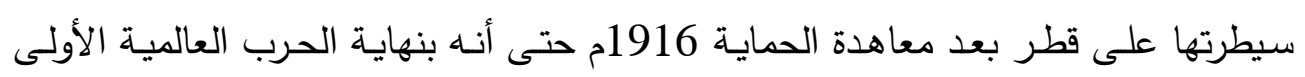
1918م كانت الدولة العثمانية قد خسرت أغلب مناطق نفوذها في الخليج ثم تلاشى الوجود العثماني في الخليج العربي نهائيًا (8).

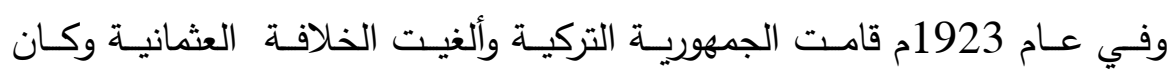
مصطفى كمال أتاتورك أول رئيس للجمهوريـة (1923-1938م) وقد تبنى فكرًا علمانيًا في

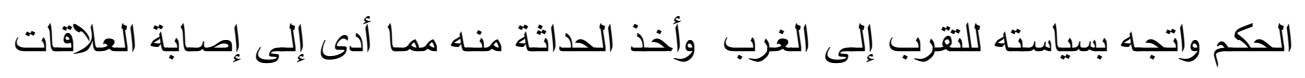

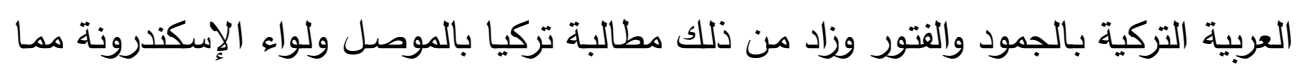
أحدث فجوة كبيرة في العلاقات العربية التركية(9). وفي الخليج العربي سعت تركيا للحفاظ على علاقات طيبة فاعترفت بمملكة نجد

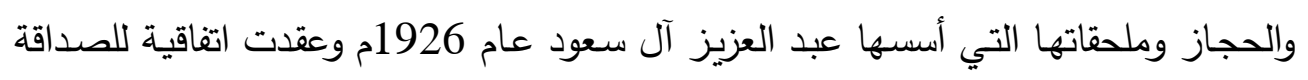
بين الطرفين 1929م غير أن اتجاه تركيا إلى إنثاء حلف بغداد 1955م مع العراق وإيران وأفغانستان أدى إلى فتور العلاقات التركية السعودية حتى عادت العلاقات الطيبة بعد انهيار

(6) Dickson, H. R.: Kuwait and her Neighbors, London, 1956, p. 118.

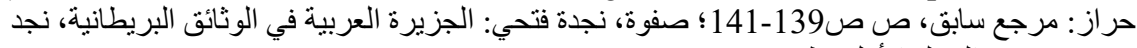

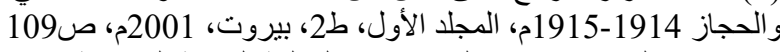

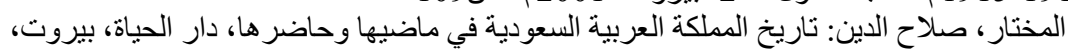

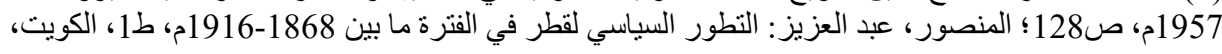

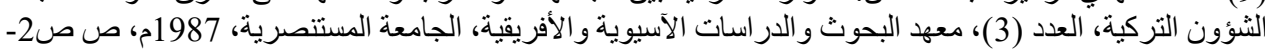




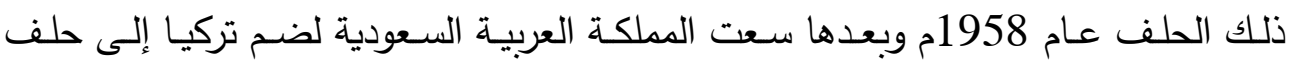
إسـلامي عام 1966م ورغم رفض تركيا إقامة أحلاف على أسـاس ديني فقد ارتفع مستوى التمثيل الدبلوماسي بين البلدين في ذلك العام إلى مستوى السفراء (10). من ناحية أخرى لم تكن هناك علاقات واضحة بين تركيا وبقية بلاد الخليج العربي نظرًا لوقوع هذه البلاد تحت الاحتلال البريطاني حتى حصلت الكويت على استقلالها عام 1961م. فرحبت تركيا بذلك في حين بقيت دول الخليج الأخرى تحت السيطرة البريطانية حتى عـام 1971م، ومـن هنـا لـم تكن لتركيـا علاقـات خليجيـة حتى هذه الفترة باستثناء علاقاتها مع المملكة العربية السعودية حتى إذا اندلعت حرب السادس من أكتوبر 1973م والتي اتضـح من خلالها أهميـة سـلاح البترول واستخدامه الاستراتيجي أخذت تركيا تعيد النظر في علاقاتها مع دول الخليج العربي (11).

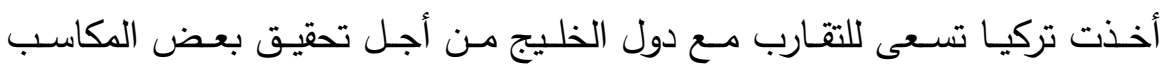
الإقليمية وقد تحقق ذلك من خلال مساندة دول الخليج لتركيا في الأزمة القبرصية الثانية عام 1974م فأقدمت تركيا على إقامـة علاقات دبلوماسية للمرة الأولى عـام 1976م مـع قطر لإنـ والبحرين والإمارات وعمان ثم أعلنت انضمامها إلى منظمة المؤتمر الإسلامي (12).

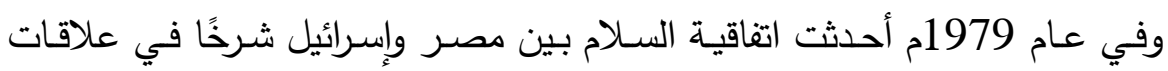
تركيا بالخليج حيث رفضت دول الخليج هذه المعاهدة مما أدى إلى تحرج موقف تركيا التي

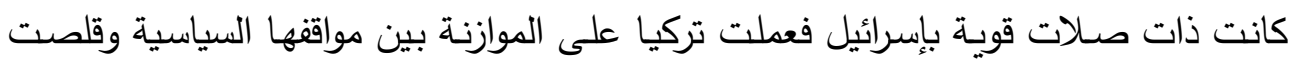
تمثيلها الدبلوماسي مع إسرائيل بعض الثيء حفاظًا على العلاقات التركية الخليجية محققة بذلك مكاسب اقتصادية كبيرة خلال فترة الثمانينيات (13).

نوفل، سيد: الخليج العربي أو الحدود الثرقية للوطن العربي، ط1، دار الطليعة، بيروت، 1969 1969م، ص123؛

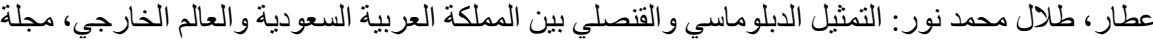

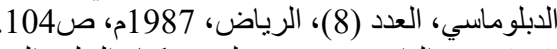

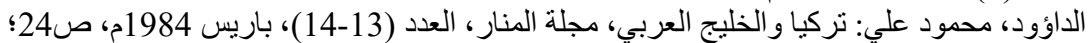

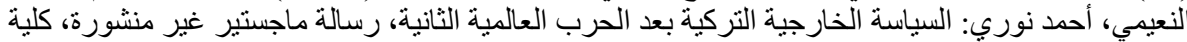

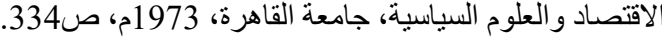

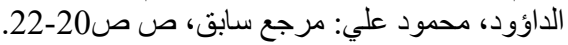

(13) Gruen, G. E.: Turkeys Relations withIsrael and itsArab Neighbors, Middle East Review, vol. 17, London, 1985, pp. 38-40; Middle East Journal, vol. 33, no. 3, 1979, p. 361. 


\section{الم موقف الحكومة التركية من حرب الخليج الأولى}

تطور العلاقات التركية بالعراق وايران :

كانت العرلق جزةً من الدولة العثمانية منذ القرن السادس عشر بعد احتلالها من

قبل السلطان سليمان القـانوني 1534م(")، و نتيجـة لذلك دخلت العراق في دائرة الصـراع العثـاني الصفوي حتى انهيـار الدولـة العثمانيـة، وبعد قيام الجمهوريـة التركيـة الحديثة بـأ تاريخ جديد للعلاقة بين البلدين، حيث تدخلت العديد من العوامل الإقليمية والدولية والمصالح

$$
\text { المشتركة في شكل العلاقات العراقية التركية(14). }
$$

سعت الجمهوريةالتركية لضم الموصل إلى الأراضي التركية؛ مما أوجد خلافاً بين

تركيا والعراق التي كانت تحت الانتداب البريطاني فتولت بريطانيا الدفاع عن موقفها، حتى عرضت القضية في عصبة الأمم التي أقرت بالإجماع على بقاء الموصل ضـمن الحدود

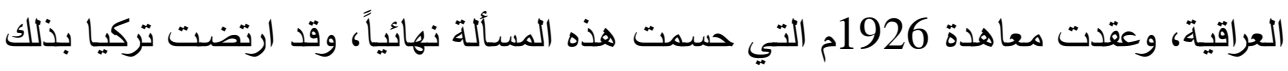

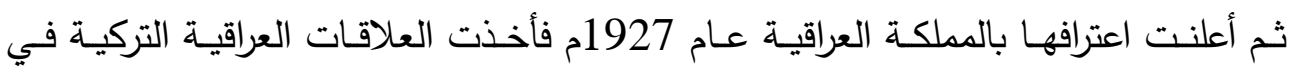
التحسن بمرور الوقت(15).

بعد هذا التاريخ وحتى قيام الحرب العالمية الثانية 1939 عقدت عدة معاهدات بين

الدولتين للتعاون الاقتصـادي وتطوير التجارة واستغلال النفط ثم عملت تركيا على تطوير علاقتها السياسية بالعراق رغبة في تكوين حلف سعد آباد عام 1937م كحلف يهدف إلى

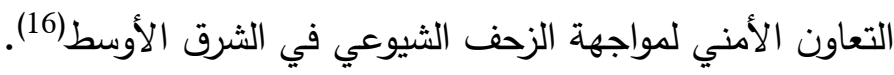

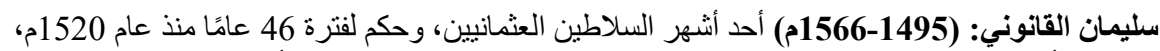

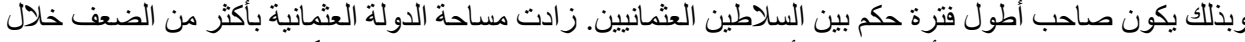

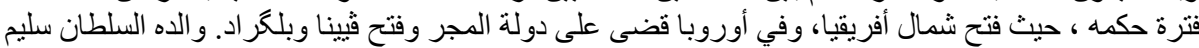

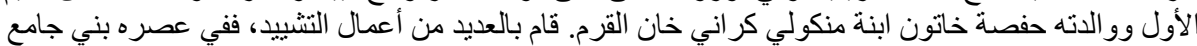

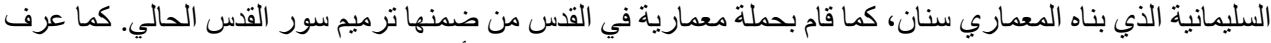

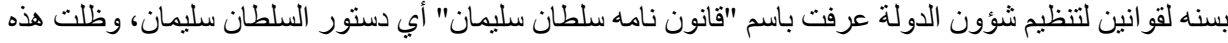

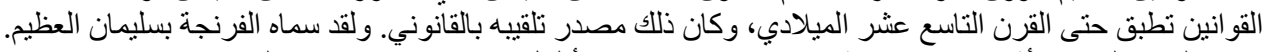

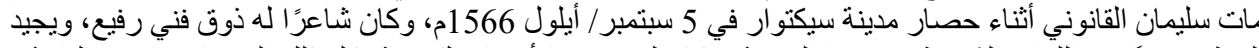

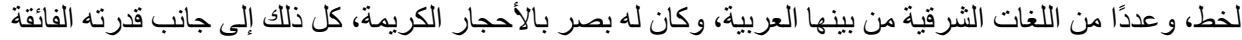

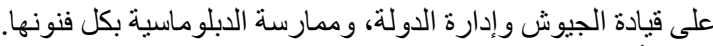

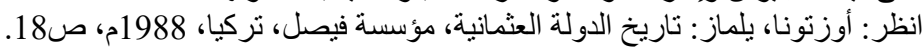

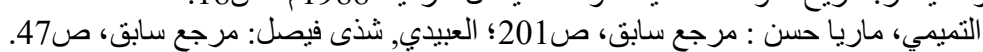

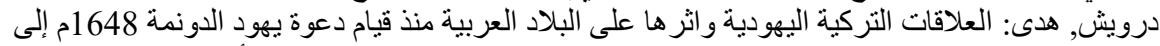

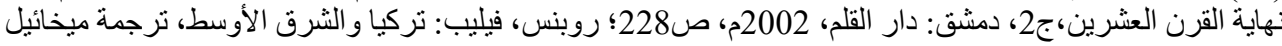

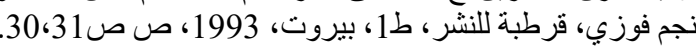

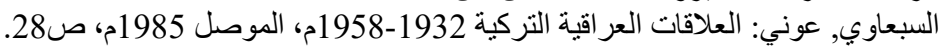


بعد الحرب العالمية الثانية عقدت معاهدة 1946م للصداقدة وحسن الجوار والتعاون

التجاري والمائي، فزاد التقارب العراقي التركي حتى كان حلف بغداد 1955م تتويجًا لتطور العلاقات بين البلدين، غير أن سقوط النظام الملكي العراقي عام 1958م تسبب في تدان هور

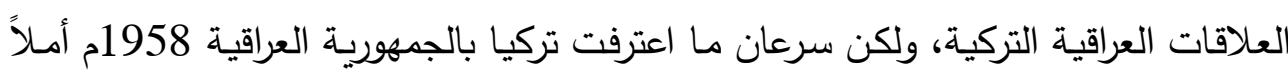
في الإبقاء على الحلف غير أن العراق أعلنت انسحابها من حلف بغداد عام 1959م بشكل رسمي (17).

بعد انهيار حلف بغداد1959 ثم قيام حركة مسلحة في العراق 1961م تدهورت العلاقات التركية العراقية مرة أخرى عندما اتهمت العراق تركيا بدعم المسلمين الأكراد. غير أن الموقف العراقي من الأزمة القبرصية الأولى عام 1965م وتصويت العراق ضد انضمام قبرص لليونانساعد على تحسين العلاقات مرة أخرى بين الطرفين(18). وخلال السبعينيات من القرن العشرين تطورتالعلاقات التركية العراقية بشكل ملحوظ تهائ حيث اعترفت تركيابشرعية الرئيس العراقي أحمد حسن البكر (1968-1979م)(")، فأخذ الأخير في التقرب الى تركيا من خلال عقد عدة معاهدات للتعاون الاقتصاديوالنفطي والأمني لبكي لترئي

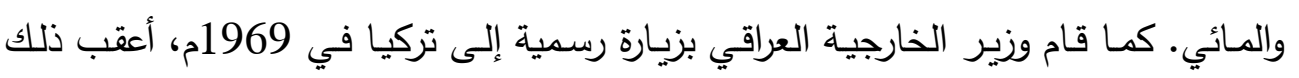

(17) Saglamer, GecenKaynak, KayhanSaglamer, BelgelerieTurk.TarihiDergisiSayi,

1972,S. 314, 315.

$$
\text { كنلك انظر : السبعاوي، عوني: مرجع سابق، صابق، ص30. }
$$

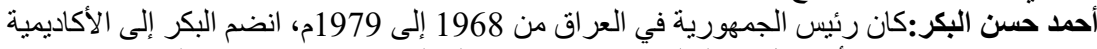

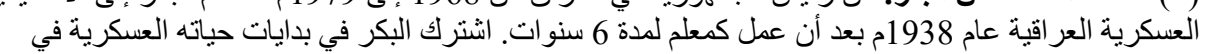

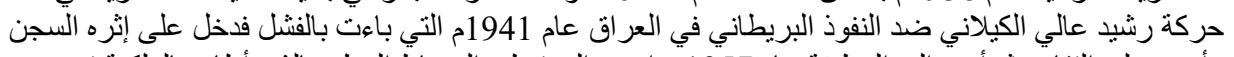

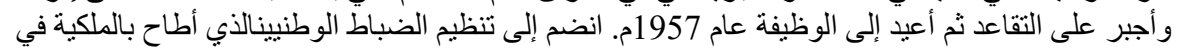

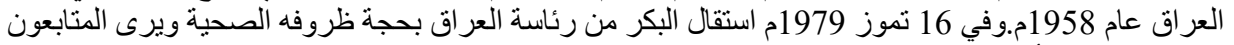

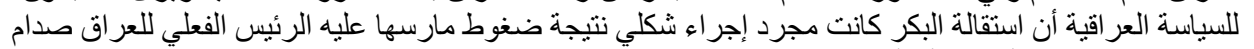

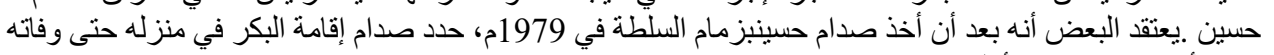

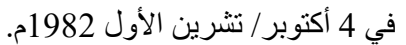

انظّر : الونداوي، مؤيد: شخصيات عر اقية في الوثائق البريطانية 1935-1958م، دار الوضاح للنشر، الأردن، عمان،

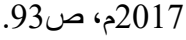

$$
\text { مجلة بحوث كلية الآداب } 2466
$$




\section{م، موقف الحكومة التركية من حرب الخليج الأولى المقالى}

زيارة قام بها الرئيس العراقي 1972م، وفي المقابل قام الرئيس التركي فخري كورتورك بزئسيارة

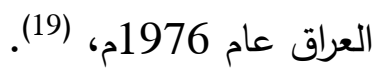

منذ عام 1974م أدت المشكلة الكردية الى توتر هذه العلاقات بعض الثـئ ولكن تعاون الحكومتين أدى إلى تجاوز الأزمة وتوقيع معاهدة صداقة جديدة عام 1978م، وبعد لمدهد

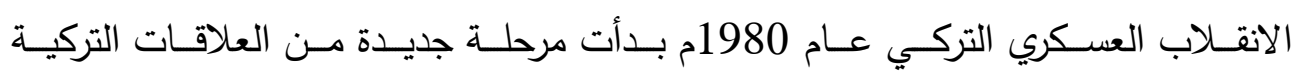
العراقيةحيث سعى قادة الانقلاب إلى تحسين العلاقات التركية العربية بوجه عام، فاستقرت

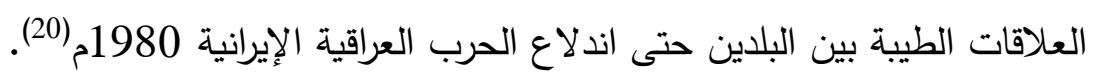

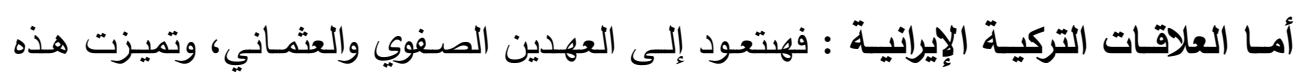
المرحلة بالمواجهات العسكرية بين الطرفين، بسبب الصراع المذهبي والتنافس السياسي وبعد إلدئ

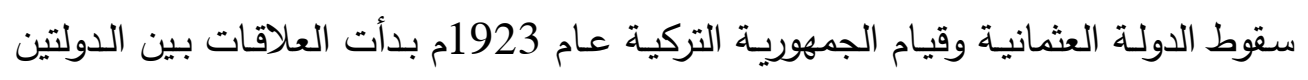
تصبح أكثر هدوءً ، خاصـة وأن ايران أبدت إعجابها بالدولتة التركية الحديثة وقد كان شـاه بـاه

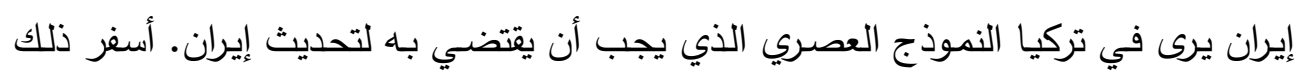

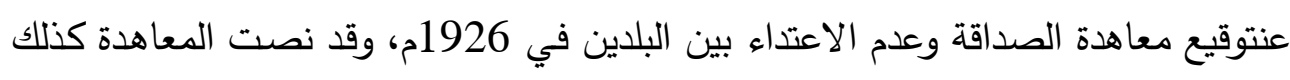
على بنود للدفاع المشتركضد أي هجوم قد يعكر صفو الأمن أو يسعى لقلب نظام الحكم فيأى من الدولتين (21).

أخذ التقارب التركي الإيرانيفى الازدياد منذ عام 1932م حيث عقدت تركيا مع إيران معاهدة الصداقة وحسن الجوار نظرًا لسياسة تركيا التي كانت ترمي لتكوين تحالفات سياسية الإدياد في الثرق الأوسط ضد النفوذ السوفييتي والخطر الثيوعي(22). كما ازدادتالعلاقات الوديـة بين مصطفى كمال أتاتورك أول رئيس لتركيا الحديثة وشاه إيران محمد رضـا بهلوي، حيث قام الأخير بزيارة رسمية إلى تركيا بدعوة رسمية من الأول 1934م، لونئ (23).

$$
\begin{aligned}
& \text { (19) الداؤود، محمود علي: نركيا والخليج العربي، مجلة المنار، العدد 13-14، كانون الثاني وشباط، 1986م، }
\end{aligned}
$$

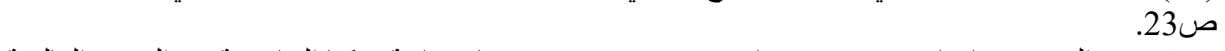

$$
\begin{aligned}
& \text { (20) التميمي، ماريا حسن: مرجع سابق، ص205؛ بونسخفيريا، سياسة تركيا الخارجية بعد الحرب العالمية }
\end{aligned}
$$

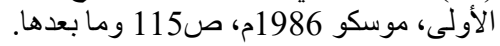

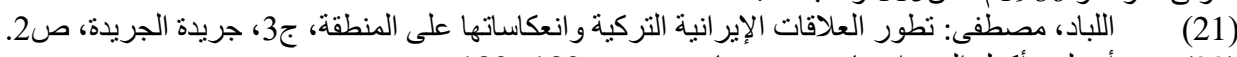

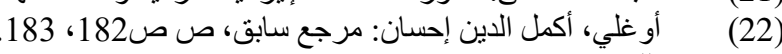

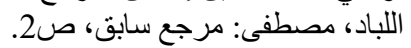


د/ هلى محمود محمد على نايل وتمشياً مـع السياسـة التركية دعت تركيا إيران إلى الانضمام لميثاق سعد آباد مـع

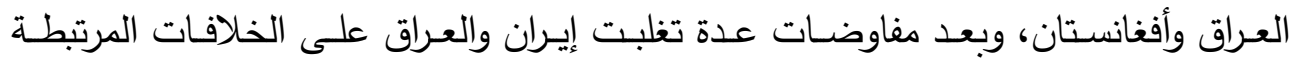

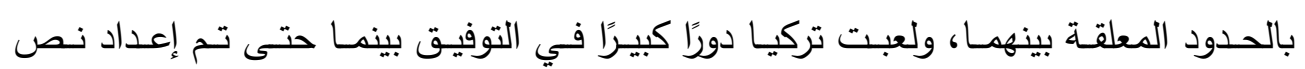
ميثاقسعد آباد 1935م، وتم التوقيع عليه 1937م (24).

وبعد الحرب العالمية الثانية 1945 اتسمت العلاقات التركية الإيرانية بالهدوء حتى عملت تركيا على ضم إيران والعراق فيما عرف بحلف بغداد 1955م، ورغم انسحاب العراق عام 1958م وانهيـار هذا الحلف بقيت العلاقات التركيـة الإيرانيـة هادئـة حتى قيام الثورة الإسـلامية 1979م، فانقطعت علاقـة تركيا بـايران نظراً لتخـوف تركيـا مـن تصـدير الثورة الإسلامية إلى أراضيها ،وعند قيام الحرب العراقية الإيرانية 1980م بدأت تركيا تععل على لئل عودة العلاقات مع ايران من جديد نظرًا لما صاحب ذلك الحدث من حدوث انقلاب عسكري في تركيـا سـعى لاسـتقطاب الـبلاد العربيـة بوجـه عـام ودول الخلـيج العربـي على وجـهـ الخصوص (25). المشكلات الحدودية بين العراق وايران - إرهاصات الحرب : تعود بدايـة رسم الحدود بين العراق وإيران إلى العصر العثماني، حيثوقعت العديد من المعاهدات بين العثانيين والصفويين من أجل رسم هذه الحدود، وبعد قيام الجمهوريـة التركية 1923م ظهر النزاع العراقي التركي حول منطقة شط العرب كأحد أهم نزاعات الحدود في منطقة الخليج العربي والذي تحول في النهايـة إلى حرب طاحنة تركت تأثيرهـا إقليميًا ودوليًا (26). يتألف شط العـرب مـن التقاء نهـري دجلـة والفـرات، ويبلـغ طولـه حوالي 180كم، وعرض مجراه بين 1-2 كيلومتر، ونصف هذه المسافة تقع في الأراضي العراقية، والنصف الثاني يصبح حدًا فاصلاً بين العراق وغيران بدءً من خور را مشهر شرق مدينة البصرة، وقد

$$
\text { بوتسخفير أكمل الدين إحسان: مرجع سابق، ص117. 187، } 188 .
$$

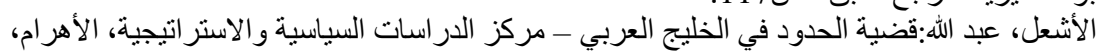

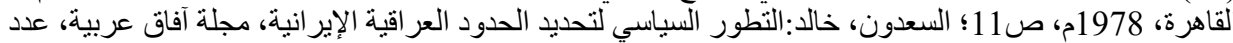

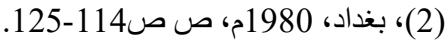




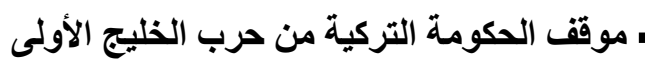

بدأت أهمية شط العرب في الظهور منذ القرن السادس عشر عندما بدأ الاستعمار الأوربى الأبى

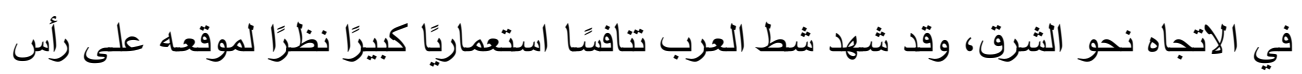

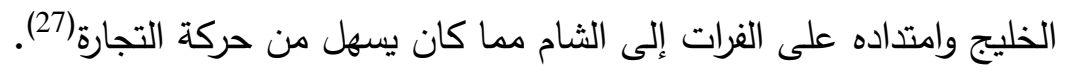

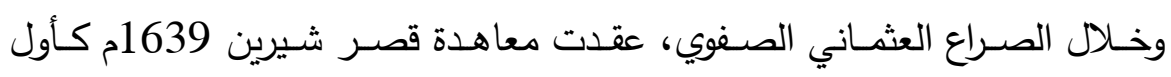

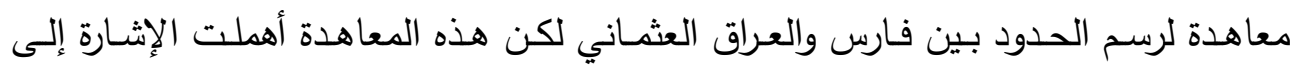

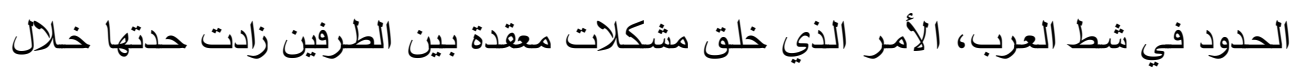

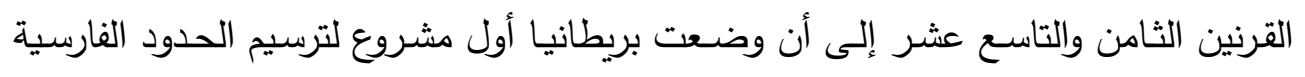

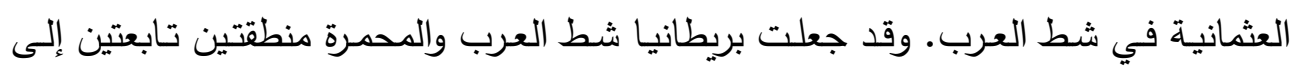
العراق العثماني (28).

عارضت روسيا المشروع البريطاني بشدة أملاً في أن تصبح شط العرب إحدى العانى

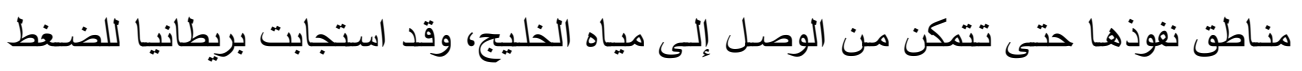

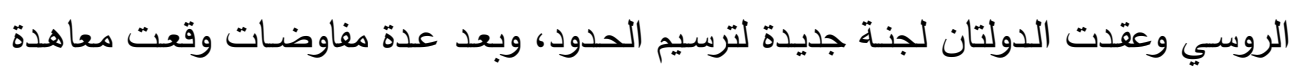

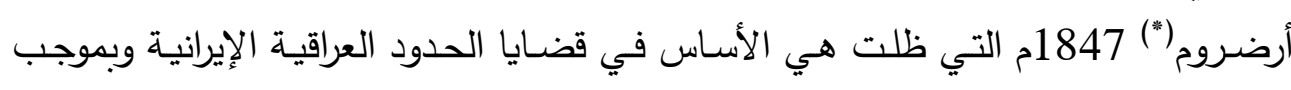
هذه المعاهدة تتازلت الدولة العثمانية لفارس عن الدحمرة وعبادان، وأكدت على على الإم تنازلها عن أراضي وموانئ أخرى (29).

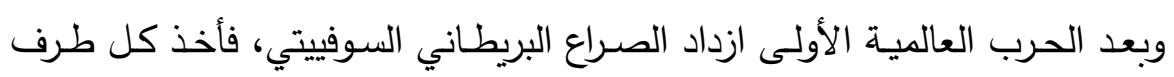

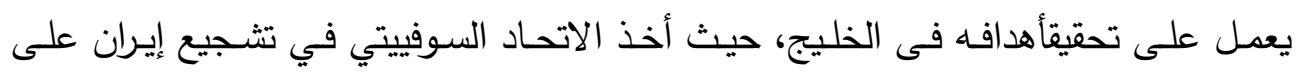

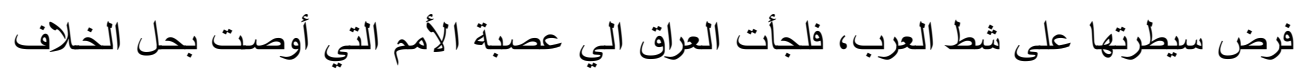

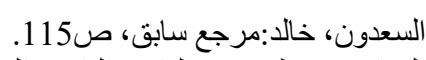

$$
\begin{aligned}
& \text { النجار، مصطفى عبد القادر: التاريخ السياسي لمشكلة الحدود الشرقية للوطن العربي في شط العرب، }
\end{aligned}
$$

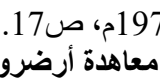

معاهدة أرضروم: 174: في مايو/أيار 1847م، وهي هي معاهدة بين الدولة القاجارية في إيران و الدولة العثمانيتسلسلة

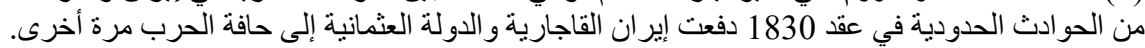

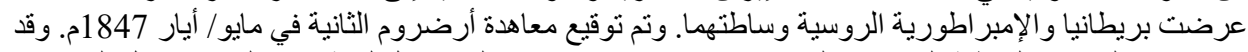

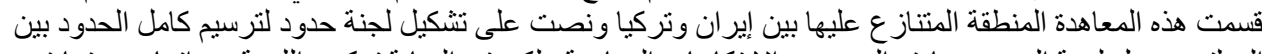

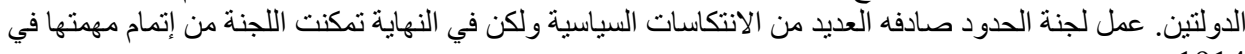

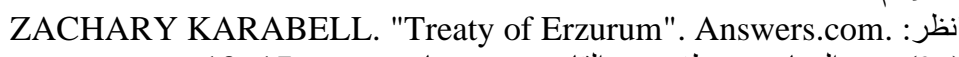
النجار، مصطفى عبد القادر: مرجع سابق، ص ص17، 18. 

من خلال التفاوض فعقدت معاهدة 1937م، حيث حصلت إيران على مكسب جديد، فأخذت سبعة كيلومترات مقابل عبادان، مع الاحتفاظ بالمعاهدة القديمة (30). وفي عام 1969م أعلنت إيران نقض معاهدة 1937م، وهددت باستخدام القوة إن لم الم تتحقق العراق مطالبها، وقد كانت مطالب إيران تتمثل في تنازل العراق عن جزء من شط العرب، لكن العراق لم يقبل، فهاجمت إيران الحدود العراقية، ثم قامت بعدة تجهيزات عسكرية

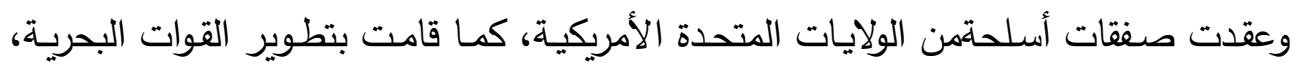
واستخدمتها للاستيلاء على جزر طنب الكبرى والصغرى وأبو موسى عام 1971م من أجل التحكم في حركة الملاحة في الخليج العربي(31). كانت معاهدة الجزائر 1975م (")هيآخر المعاهدات العراقيـة الإيرانيـة لحل مشكلة

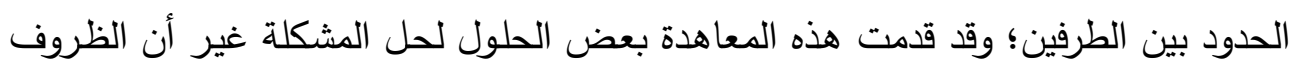
السياسية للدولتين سارت في اتجاهين مختلفين؛ مما أدى إلى زيادة النزاعات الحدودية بينهما،

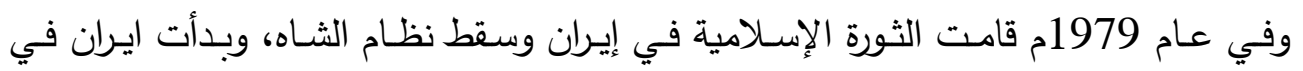
الاعتداء على الأراضـي العراقية مما أدي إلى قيام العراق بإعلان حربًا رسمية على طول

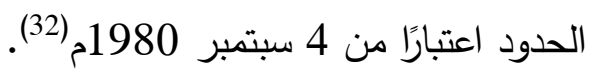
موقف الحكومة التركية من النزاع العراقي الإيراني حول الحدود : لعبت الحكومة التركية-منذ ثلاثينيات القرن العشرين - دورًا ملموساً في الوساطة بين التراني العراق وتركيا لحل نزاعات الحدود بينهـا عندما كانت تركيا ترمي إلى تحسين علاقاتها

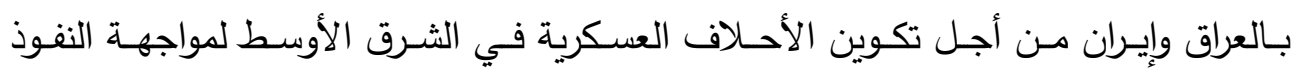
السوفييتي، وبينما كانت تركيا تعمل على إنشاء ميثاق سعد آباد( تركيا - العراق - إيران - أنسان أفغانستان) ، إذا بالنزاع العراقي الإيراني يتفاقم إلى اشتباكات حدوديـة ؛ ممـا هدد المشروع إنياء

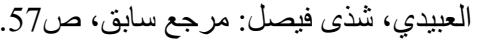




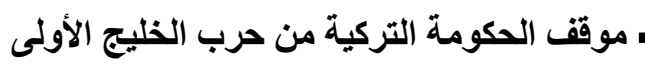

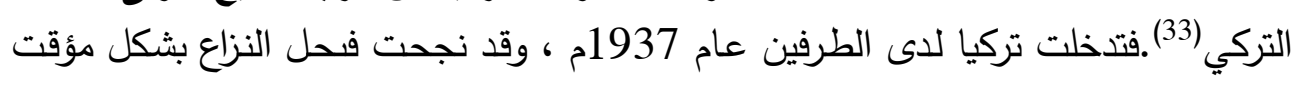
من خلال سلسلة من المفاوضات (34).

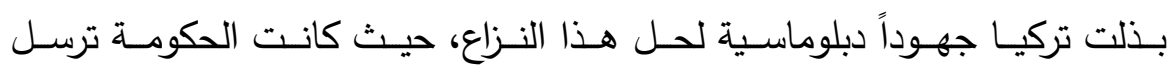
برقيتينيوميًا، واحدة إلى سفيرها في بغداد والأخرى إلى سفيرها في طهران لإبـلاغ حكومتى دئى الدولتين بوجهة النظر التركية في هذا الأمر ، كما قام السفير التركي في طهران بمقابلة وزير لهير خارجية إيران أكثر من مرة ثم التقيالثاه الإيرانى ليقنعه بضرورة إنهاء النزاع، (35).

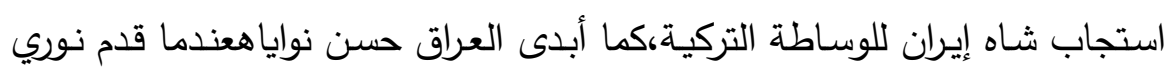
السعيد إلى وزيـر إيـران المفوض في العـراق مقترحـات الحكومـة العراقيـة النهائيـة في هذه المشكلة باعتبارها أقصى مـا يمكن للعراق أن توافق عليه، وقد ارسل الوزير الإيراني إلى حكومته بالمقترحات العراقيتوقدوافقت الحكومة الإيرانية عليها، فتم توقيع اتفاق بين البلدين في العراق عام 1937م، لتسوية النزاع الحدودي على أن تترك التفاصيل والاتفاق النهائي لإنهائها في طهران (36)وعلى أثر ذلك قام وفد رسمي من العراق بالسفر إلى طهران لإنهاء

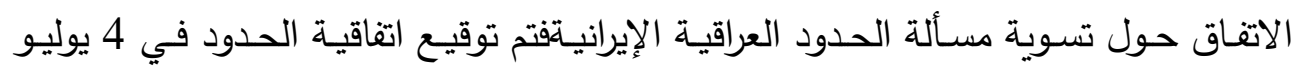
(37) 1937

$$
\text { حرب الخليج الأولى وموقف تركيا المحايد : }
$$

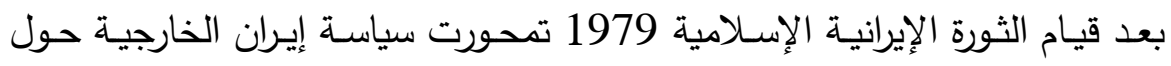

تصدير الثورة إلى خارج الحدود الإيرانية من أجل تطبيق النموذج الإيراني في سائر البلاد

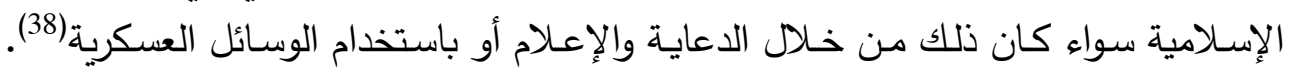

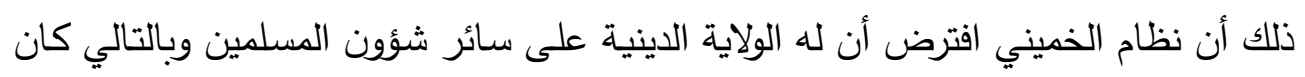

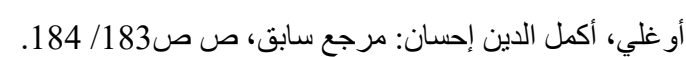
وزارة الخارجية، الأرشيف السري، محفظة 243، الكود الأرشيفي: 036002-0078، بتاريخ 5 يوليو

و وثائق عابدين، محفظة 123، الكود الأرشيفي: 002548-0069، بناريخ الكاريخ 14 سبتمبر 1935م.

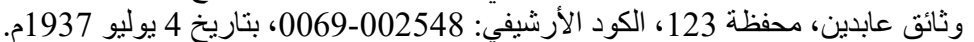

(37) TahsinÜnal, TürksiyanÎTarihi, 5 Baski, EmelYayinlari, Ankara, 1978, S. 592, 593. العبيدي، حسيب عارف: العراق ودول الجوار غير العربي، سلسلة المائدة الحرة، بيت الحكمة، العراق 
على إيران أن تعمل على نشر ثلى مدرتها بدايةً داخل حدود الدول المجاورة لها وكانت العراق هي أولى هذه الدول المستهدفة من النظام الإيراني (39).

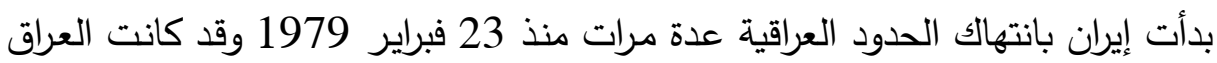

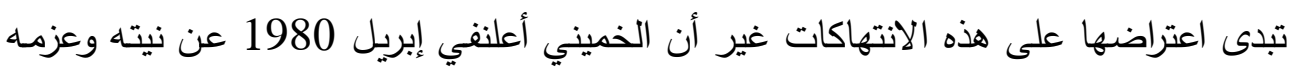

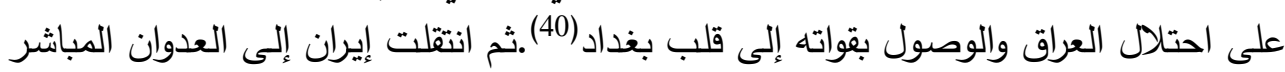

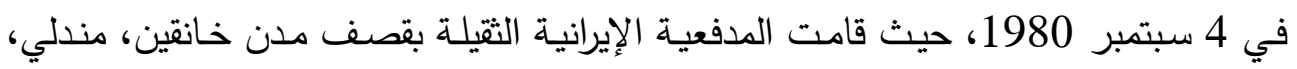

زرباطية، نفط خانة وغيرها، وعززت إيران ذلك القصف بحشود عسكرية على الحدود (41).

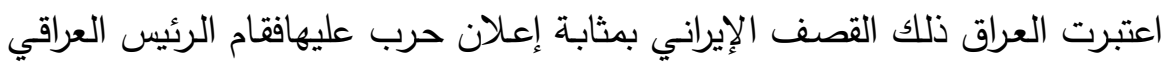

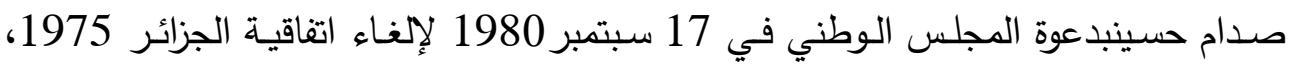
نظراً لإخلال إيران بعلاقات حسن الجوار وعدم الالتزام بالاتفاقية(42).

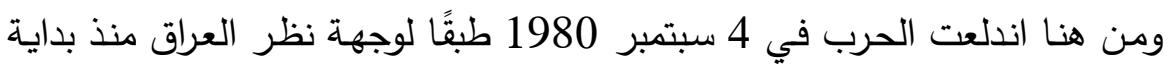

القصف الإيراني للمدن العراقية، ثم دارت الاشتباكات بين الطرفين منذ 22 سبتمبر (43).

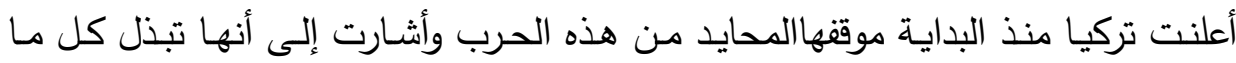

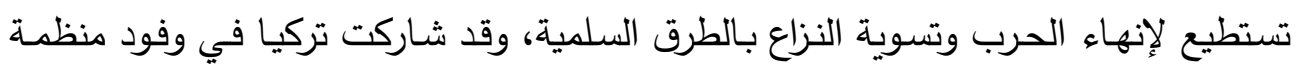

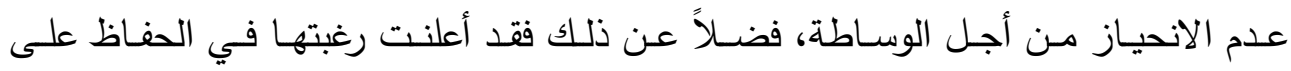

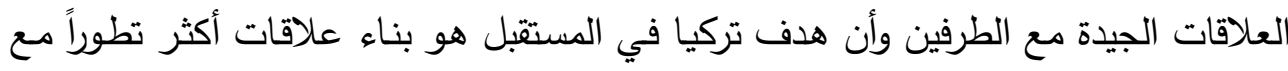

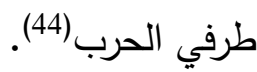

(39) السويداني، حامد محمد: العلاقات العر اقية التركية 1980 - 1990، رسالة ماجستير غير منشورة، كلية

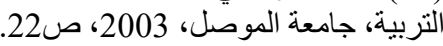

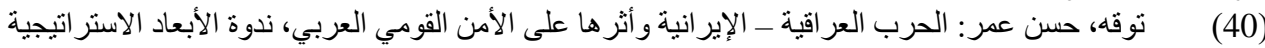

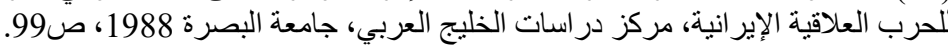

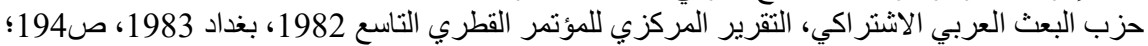

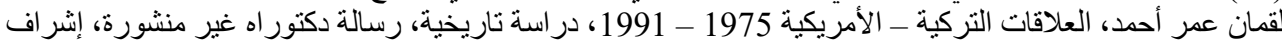

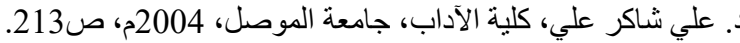

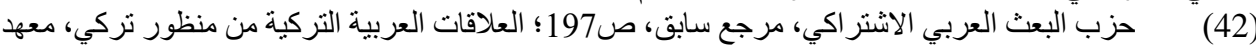

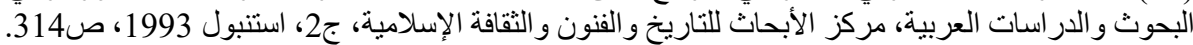

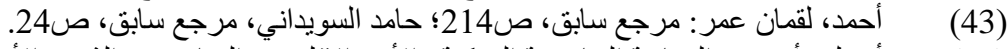

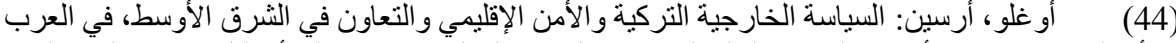

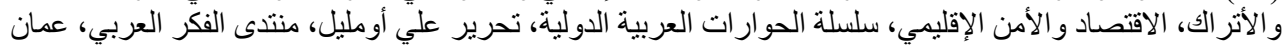

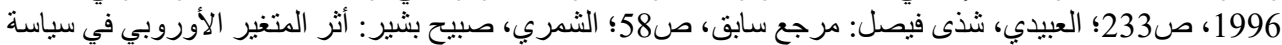

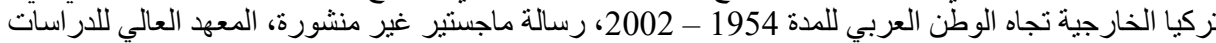

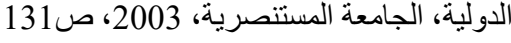


موقف الحكومة التركية من حرب الخليج الأولى لفى

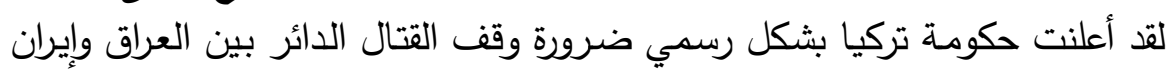

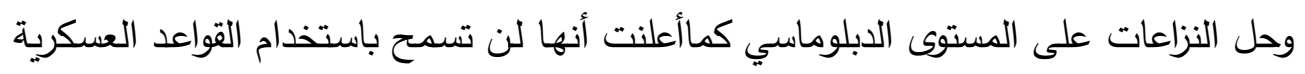

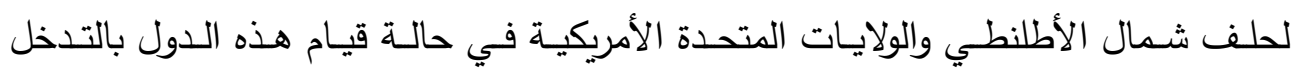

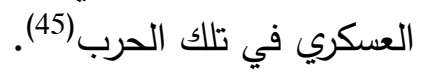
طبقًا لذلك أعلنت وزارة الخارجية التركية في 1980 "أن تركيا ستبقى على الحياد

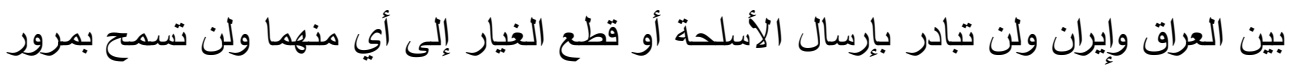

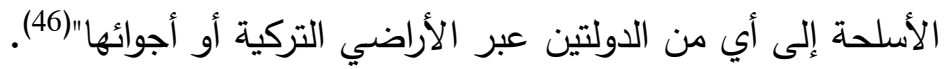

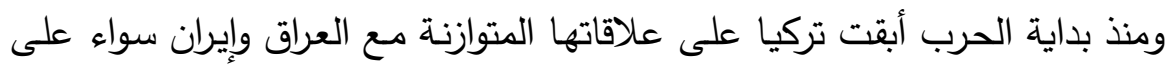

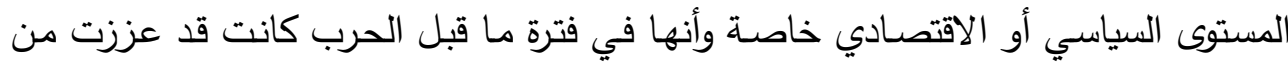

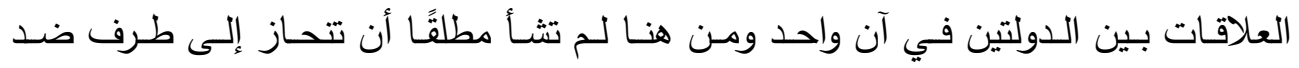
الآخر (47).

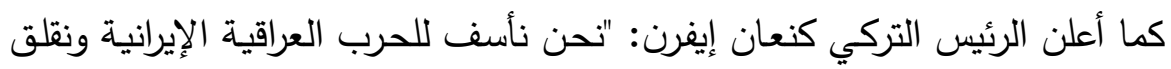

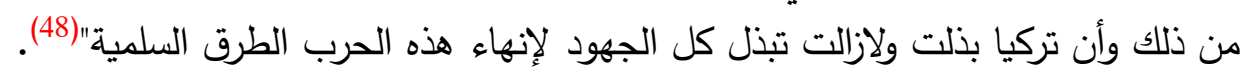

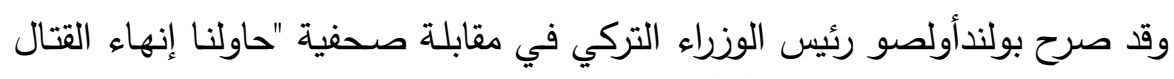
لكننا لم نتمكن من تحقيق نتائج إيجابية(49).

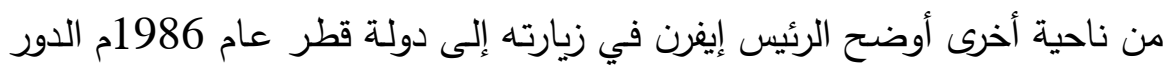

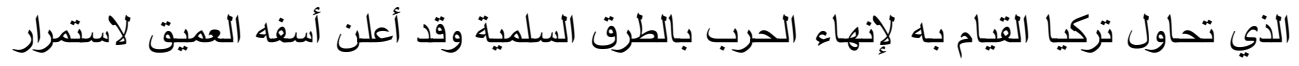

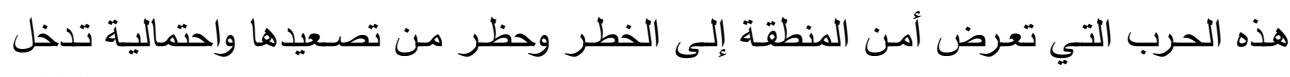

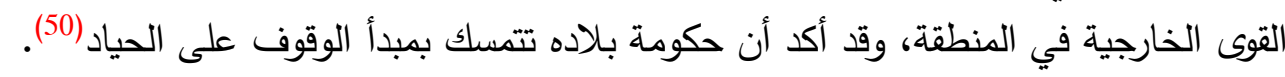

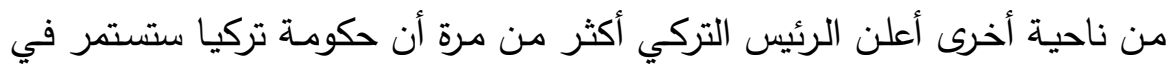

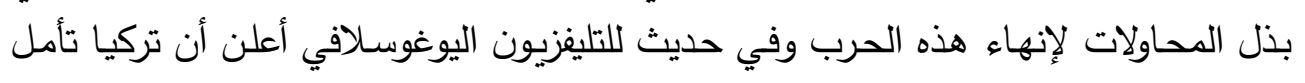


د/ هلى محمود محمد على نايل

في إنهاء الحرب وتئابع بقلق استمرار المعـارك التي بدأت تؤثر بالفعل على السـلام في

المنطقة (51).

أسباب الحياد التركي ونتائجه :

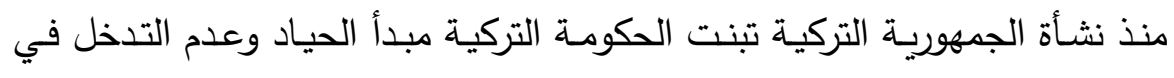

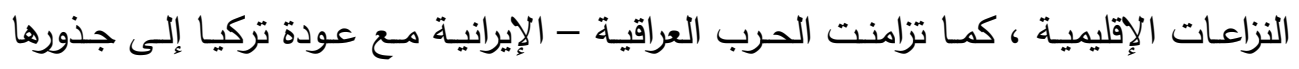

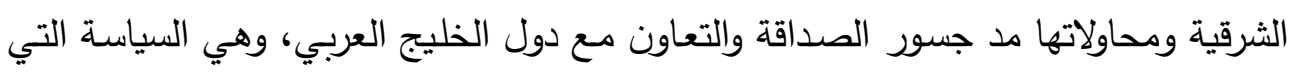

اتبعتها تركيا بعد حرب 1973 وبروز أهمية الخليج العربي، وفي خلال ذلك دولك عملت تركيا على البحث عن دور سياسي يعكس هذه الصورة ويؤكد على رغبتها في التعاون مـع البلاد

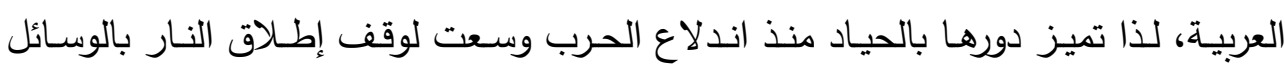
الدبلوماسية (52).

وقد لعب الموقع الجغرافي لتركيا دوراً بارزاً في تحديد أهمية الدول المجاورة خاصـة

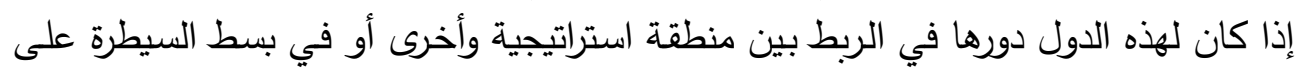

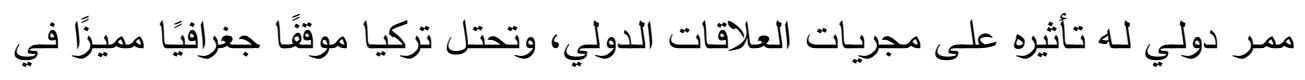

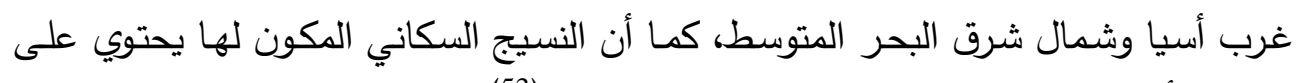
بعض الأقليات العربية والكردية في جنوب وشرق تركيال(53).

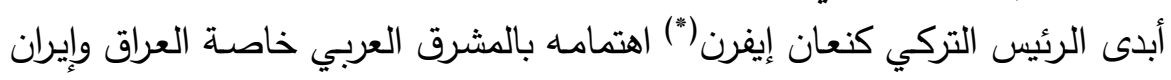

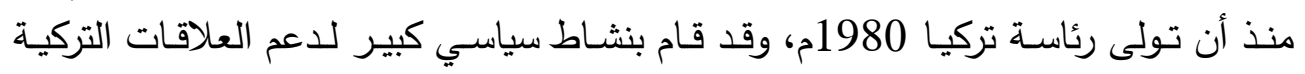

(52) Saglamer, GecenKaynak, op. cit., S. 422.

$$
\text { جريدة العراق، بغداد، العدد (6246)، 1984م. }
$$

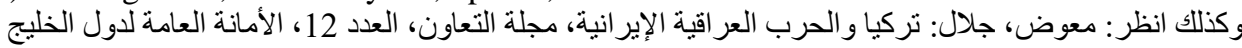

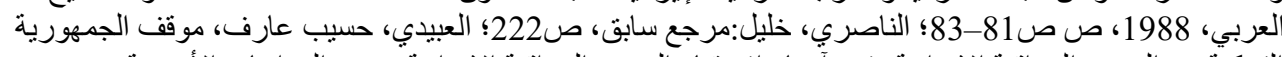

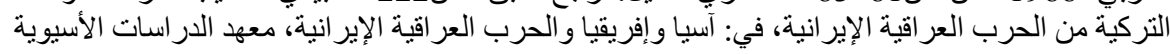

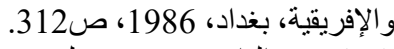

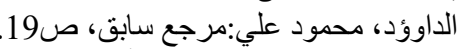

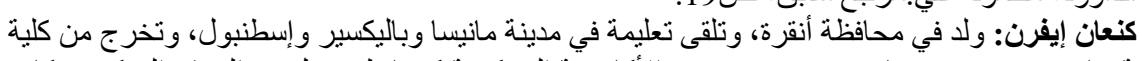

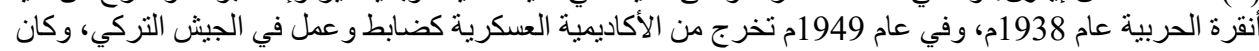

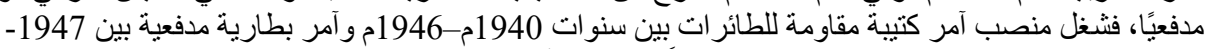

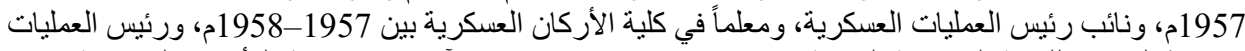

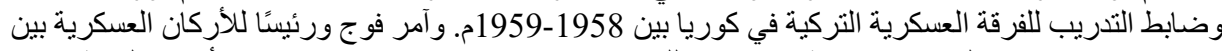

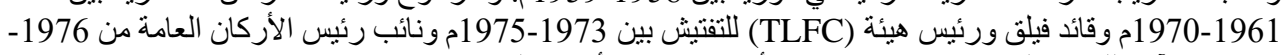

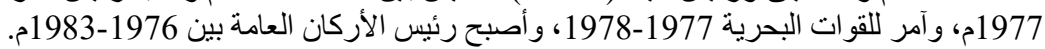

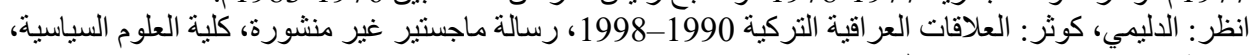

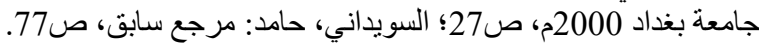




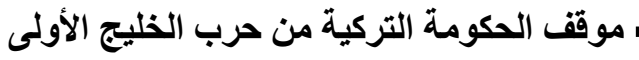

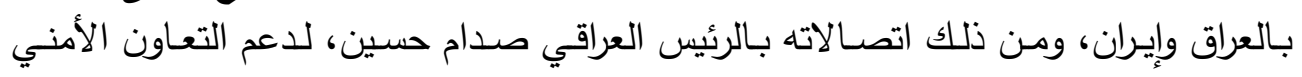
والاقتصادي بين البلدين (54). وقد كانت تركيا تدرك أهمية السلام في الدنطقة حفاظًا على مصالحها في الخليج

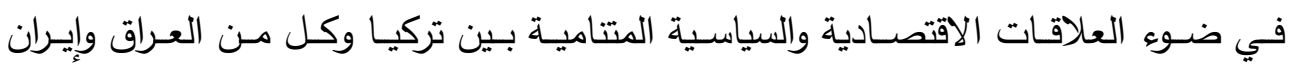
والسعودية ودول الخليج(55). المؤثرات الدولية والإقليمية :

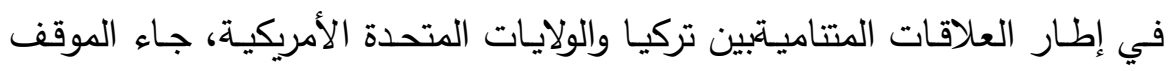

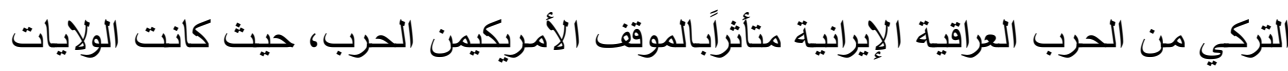

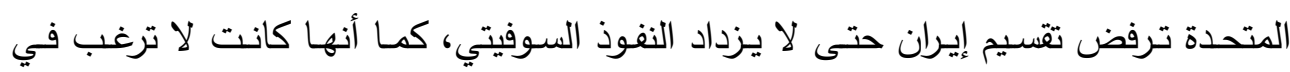

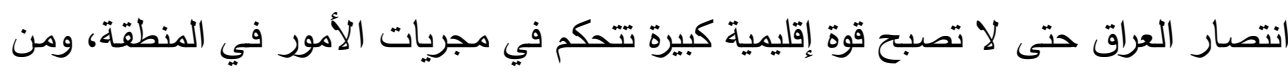

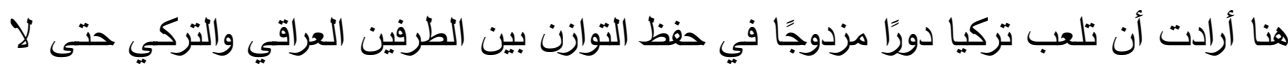

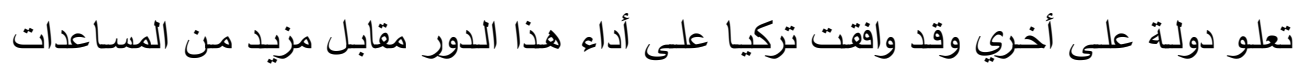
الأمريكية، (56).

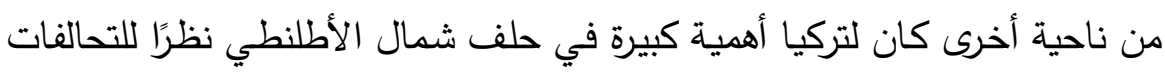

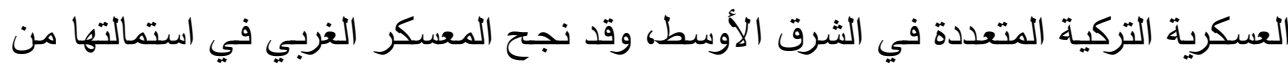

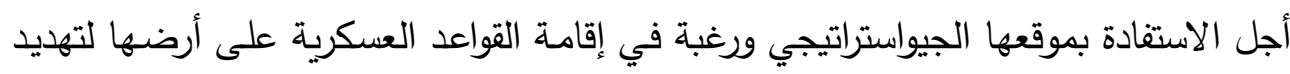

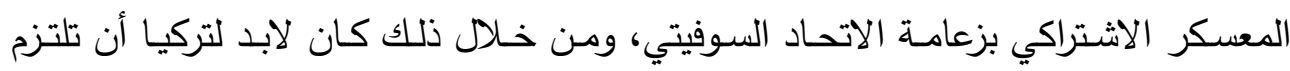

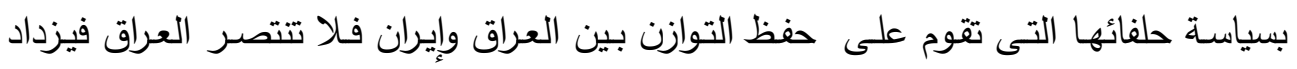
نفوذها ولا تتنصر إيران فتتاهض المعسكر الغربي (57).

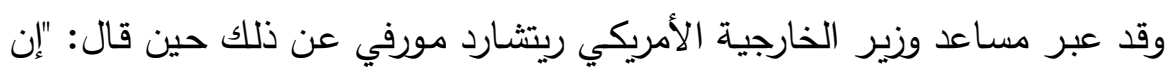

انتصار أي طرف غير ممكن وغير مرغوب فيه استراتيجيًا" (58).

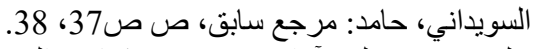

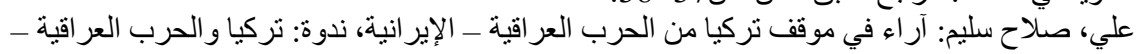

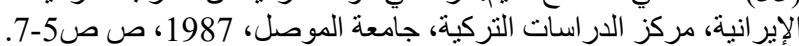

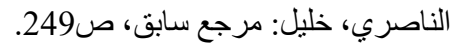


على الصعيد الإقليمي كان استقرار المنطقة أحد التوجهات المهمة في سياسة تركيا، حيث السـلام يدعم المصـالح التركية، وعلى النقيض من ذلك يؤثر النزاع كثيرًا على أحوال

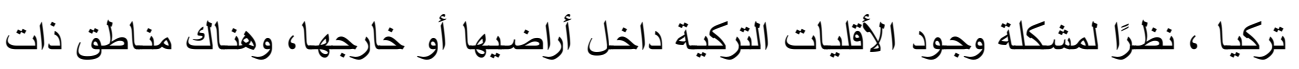

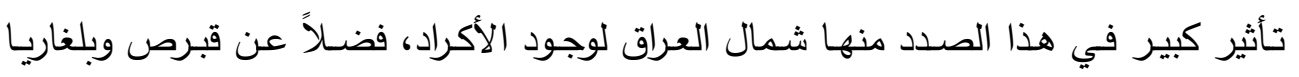
ومقدونيا وأذربيجان في إيران (59).

ونظرًا لأن تركيا كانت مجاورة لطرفي النزاع فإن حالة الاستقرار الإقليمي تؤثر على إنى

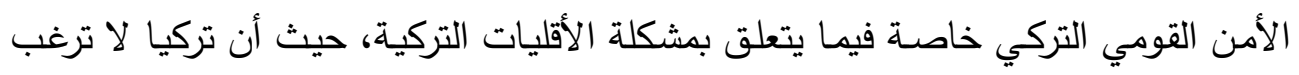

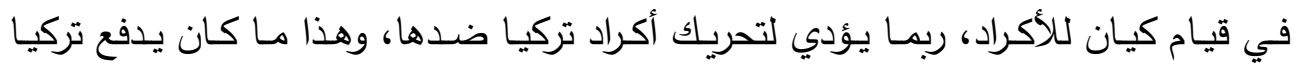
لمساعدة العراق وإيران في القضاء على الحركات الكردية المسلحة التي حدثت في الدولتين قبل ذلك (60).

وقد تخوفت تركيا كذلك من تطور النزاع العراقي الإيراني إلى الحد الذي يدفع بها

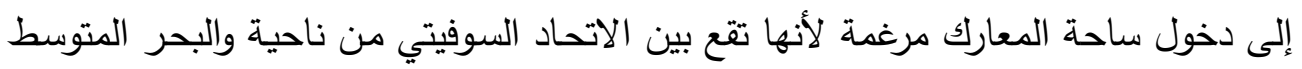

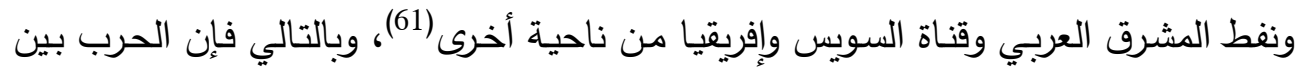

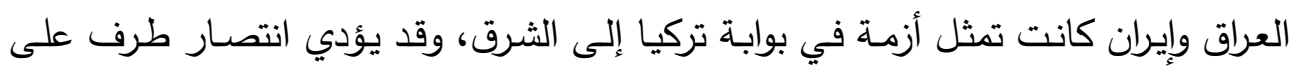
الآخر إلى ضــط إقليمي عليها في الوقت الذي تعاني فيها من ضـغوط الاتحساد السوفيتي واليونان (62.).

كانت العراق وإيـران فضـلاً عن سوريا قوى إقليميـة نشطة تسعى كل منهـا لبسط نفوذها الإقليمي وترى في تركيا قوة رابعة منافسة تعمل من أجل ذلك، لذا فإن زيادة نفوذ أيًَا من هذه الأطراف قد يؤثر سلبًا على قوة تركيا ونفوذها الإقليمي(63). من ناحية أخرى كان استمرار الحرب من وجهة النظر التركية يمثل تربـة صـالحة لبروز الجماعات اليسارية واليمينية على حد سواء، كما يؤثر على سياسة تركيا النشطة في

$$
\begin{aligned}
& \text { (59) الناصري، خليل: السياسة الخارجية التركية إزاء الثرق الأوسط للددة الو اقعة من 1945-1991م، }
\end{aligned}
$$

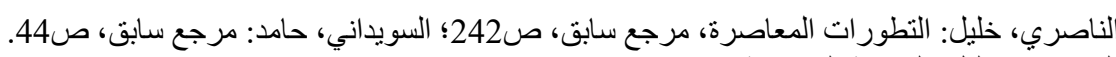

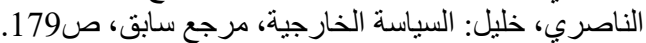

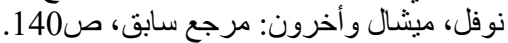

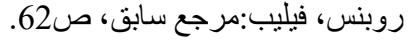

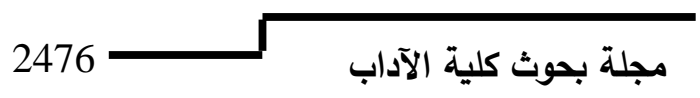


موقف الحكومة التركية من حرب الخليج الأولى

الوطن العربي خاصـة أن البلاد العربية انقست بين مؤيد ومعارض فدعمت كل من سوريا

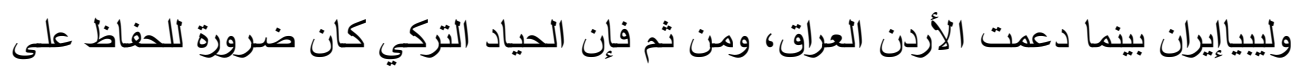
التوجهات التركية في الوطن العربي ولاستمرار العلاقات التركية العربية دون اهتزاز (64).

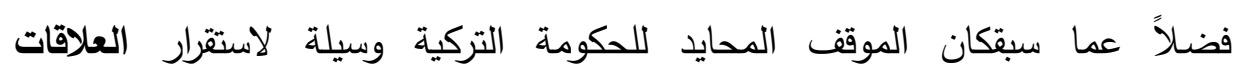
الاقتصادية بين تركيا والعراق وايران بحيث لا تخسر تركيا أيًا من الطرفين، فهما مصدرًا

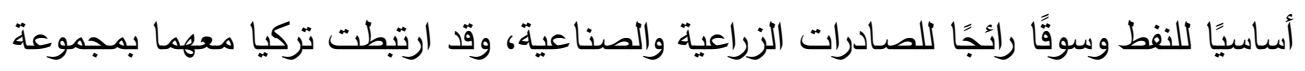

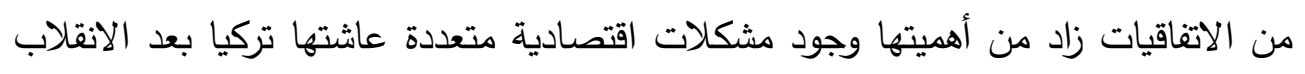
العسكري 1980 والذي دفع الحكام العسكريين في تركيا إلى إيجاد حلول تعطي لانقلابهم الشرعية (65). المكاسب التركية من الحرب: حقت تركيا مكاسب كبيرة من حرب الخليج الأولى وقد نجحت في الحفاظ على حيادتها مدة الحرب الثمانية، وبذلك الموقف تمكنت من تحقيق مكاسب تجاريـة كبيرة زادت

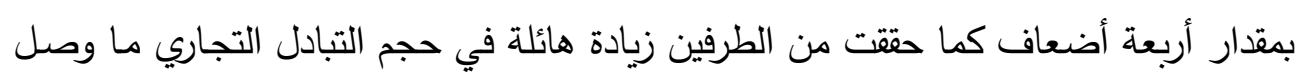

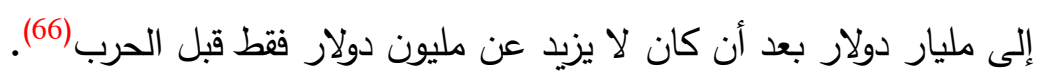
وقد كانـت نقطـة التطور الحقيقيـة في الازدهار الاقتصـادي التركي عـام 1980م

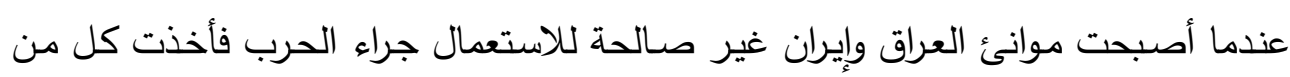
طهران وبغداد تتطلع إلى تركيا لتكون بمثابة طريق لمرور الواردات (67). من ناحية أخرى فقد حرصت تركيا على إقامة علاقات اقتصـادية مع إيران لتأمين

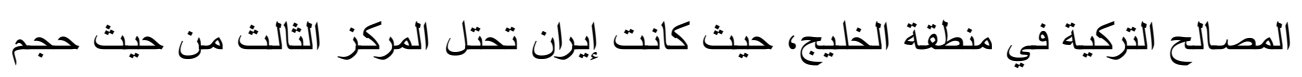
الاستيراد من تركيا وذلك بعد العراق الذي احتل المركز الثاني، وفي عام 1980م بلغت فئت قيمة

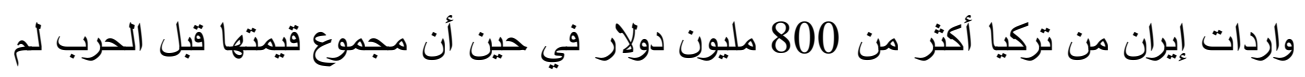


تتجاوز 28 مليون دولار ، ثم ازداد هذا الرقم بشكل كبير عـام 1981م إلى مـائ يقرب مـن

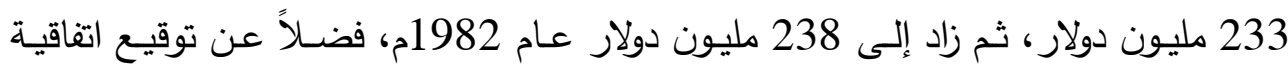
ثنائية بين تركيا وإيران في نفس العـام لتزويد إيران لتركيا بما يتراوح من 60-100 ألف دونف برميل من النفط يومًا. وقد وصف بانولي وزير الصناعات الثثيلة الإيرانية هذه الاتفاقية بأنها أكبر صفقة وقعتها إيران مع دولة أجنبية(68). وخلال الحرب اتسع النشـاط والتبادل الاقتصـادي بين تركيا وإيران حتى امتد إلى إلى شـركات النقـل البحري لنقل الـفط مـن جزيـرة خـرج الإيرانيـة إلى تركيـا كمـا ازدادت تجـارة الترانزيت من خلال نقل الثاحنات التركية سنويًا ما لا يقل عن ثلثي تجارة الترانزيت الإيرانية من مواني تركيا التي تطل على البحر الأسود (69). وفي عام 1982م انقلب وضـع الميزان التجاري التركي فأصبح لصـالح تركيا نتيجة زيـادة الاستيراد الإيرانسي والعراقي مـن تركيا حتى عقدت اتفاقيـة 1988م لإقامسة التعـاون المشترك بين تركيا وإيران في مجال النفط والغاز الطبيعي والطاقة (70). وهكذا فإن سياسة الحياد التي اتخذتها الحكومة التركية تجاه حرب الخليج الأولى قد ولدان حقتت لتركيا مكاسب اقتصادية كبيرة سواء من خـلال التعاون مع العراق أو من إيران. فقد

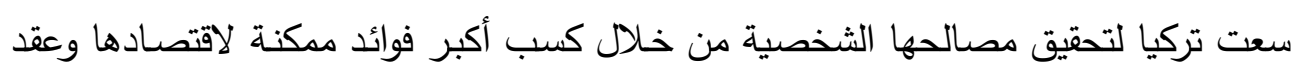
العديد من المعاهدات والاتفاقيات التجاريـة والاقتصـادية حتى تطور الاقتصـاد التركي بشكل كبير وزادت مكانة تركيا الإقليمية بسبب هذه الحرب(11).

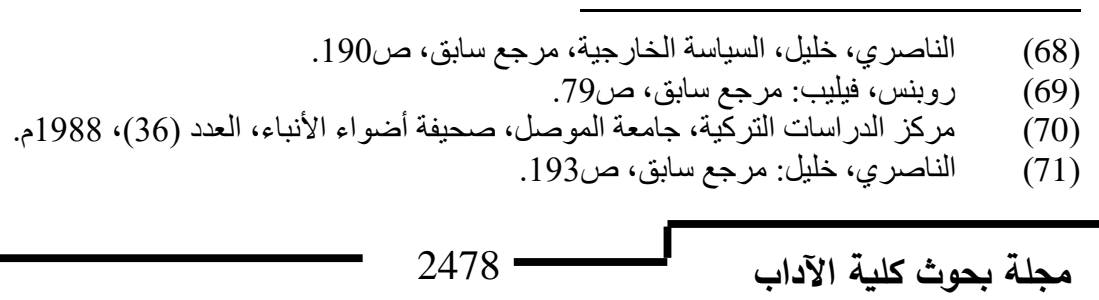


- موقف الحكومة التركية من حرب الخليج الأولى

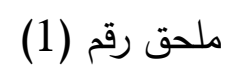

اتفاقية الجزائر بين العراق وإيران 1975م

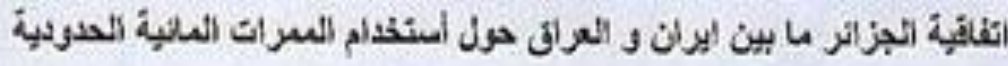

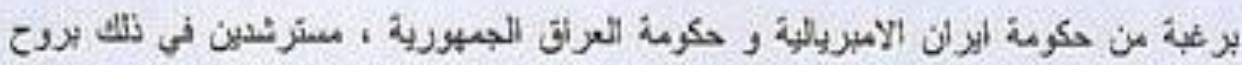

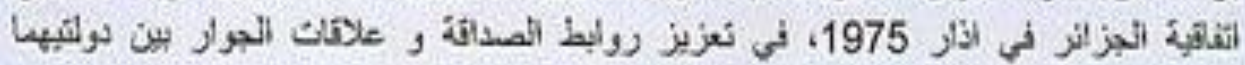

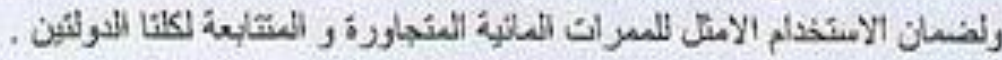

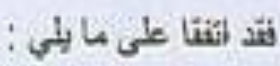

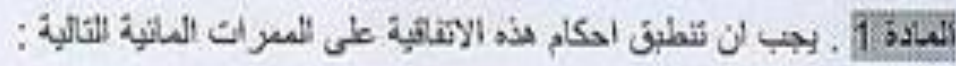

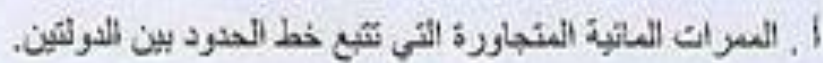

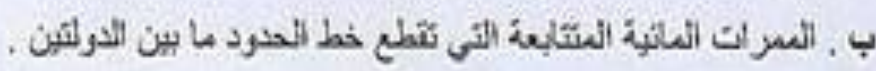

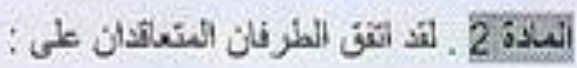

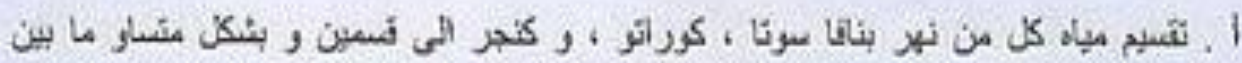

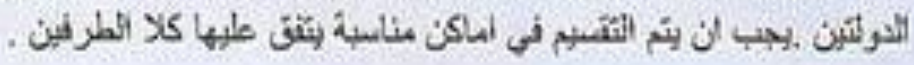

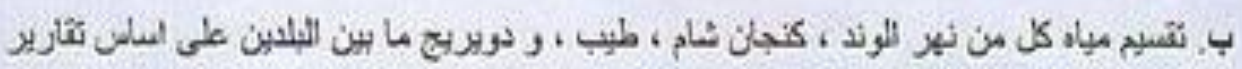

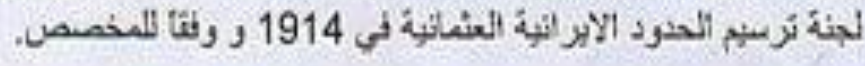

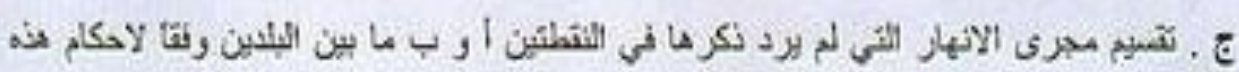

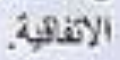

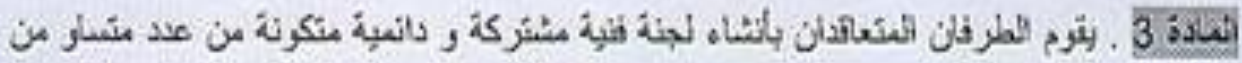

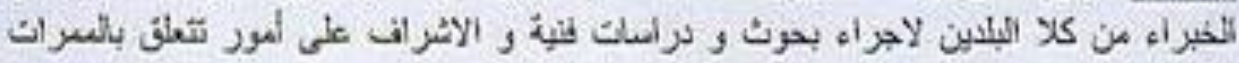

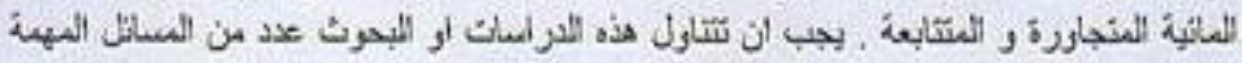

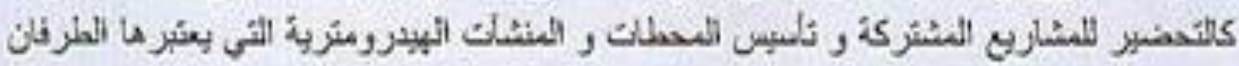

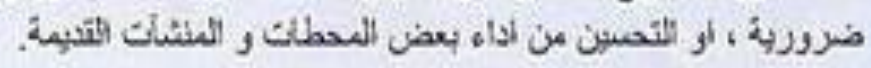




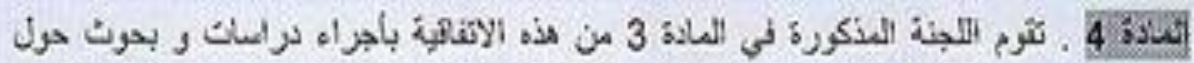

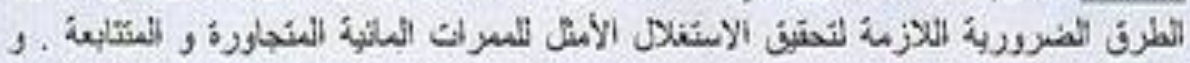

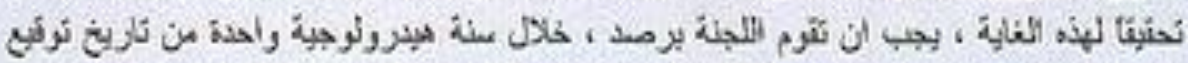

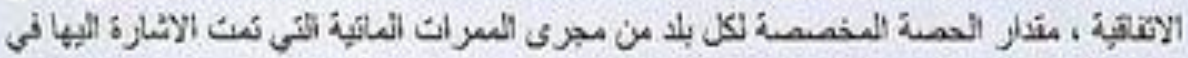

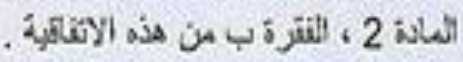

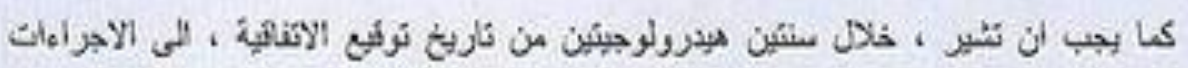

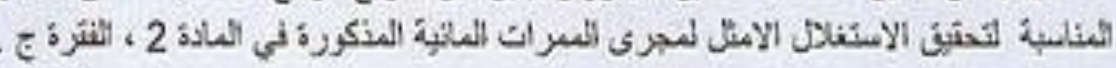

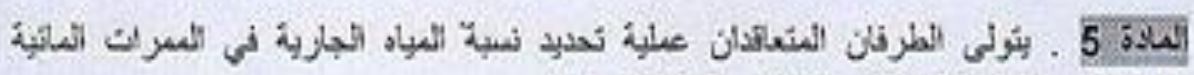

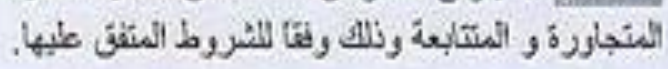

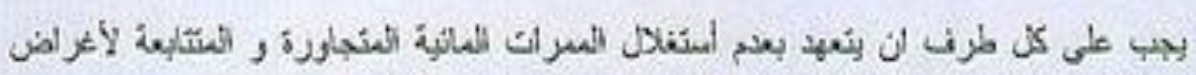

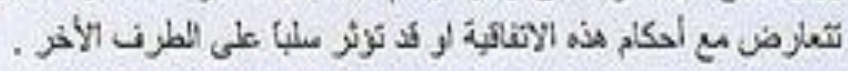

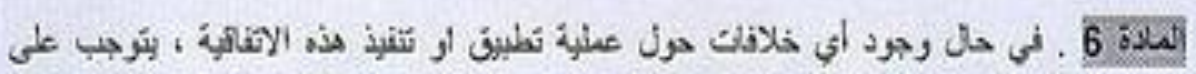

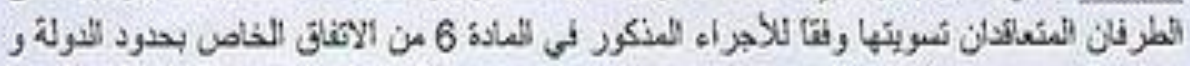

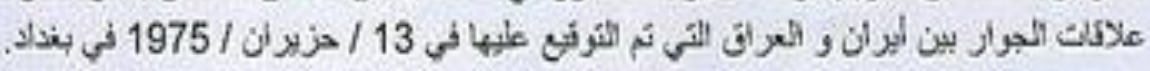

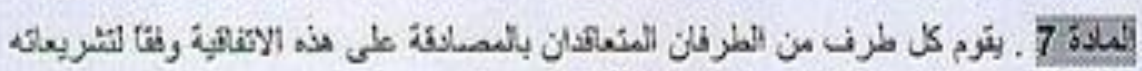

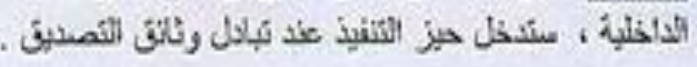

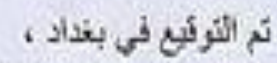

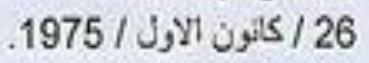

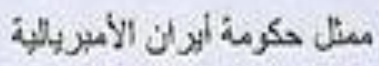

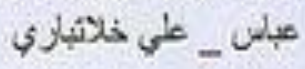

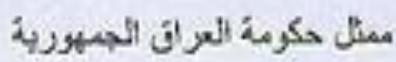

$$
\begin{aligned}
& \text { سمدرن حلدي }
\end{aligned}
$$




\section{موقف الحكومة التركية من حرب الخليج الأولى}

\section{ملحقرقم (2)}

$$
\text { بين الولايات المتحدة الأمريكية وتركيا الداقيادي }
$$

تجدد حكومتا الولايات المتحدة وتركيا تأييدهما لمبادئ وأهداف دستور الأمم المتحدة. تهدف علاقات التعاون بين الدولتين إلى الإقرار بمبادئ الديمقراطية وحقوق الإنسان.

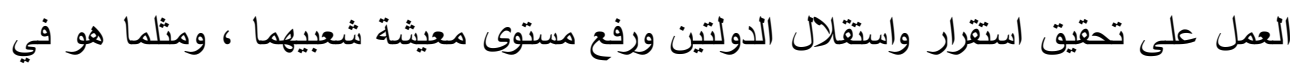
بقية مجالات الاقتصاد والدفاع فإن التعاون يقر أيضا احترام سيادة الدولتين.

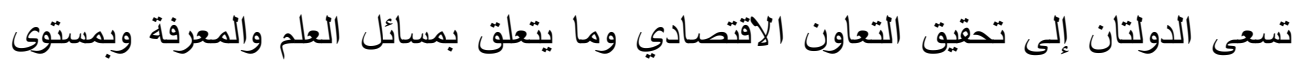
واحد في إطار معاهدة حلف شمال الأطلسي. تؤيد الدولتان مشاركتهما في إقرار السلام العالمي. تثكل الدولتان عنصرا أساسيا من عناصر إقرار الأمن والاستقرار العالمي. المشاركة الفعالة في عملية تخفيض سباق التسلح.

(1) (المادة (1) (1) تسعى الدولتان إلى اعتماد مبدأ العدالة والمساواة في تحقيق التطور الاقتصادي والاجتماعي

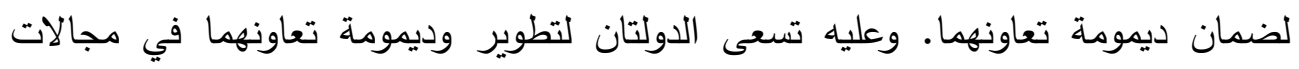
الاقتصاد والدفاع والنواحي المتعلقة بهما كعلوم الدعرفة.

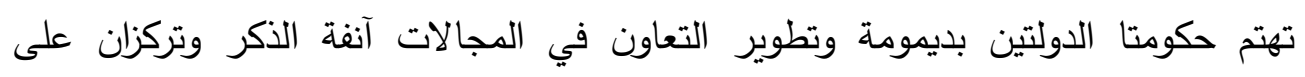

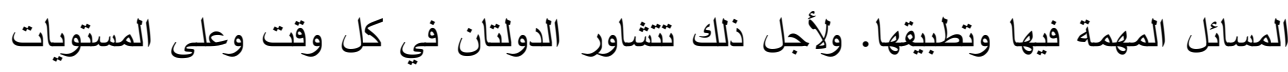
كافة لتحقيق هذه الغايات.

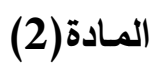
بالنظر لتقارب مسائل الاقتصاد والدفاع فيما بينهما ، واعتماد اقتصاد ودفاع متين ، تتعاون

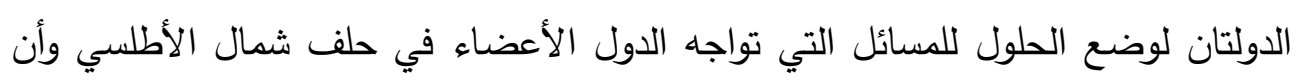

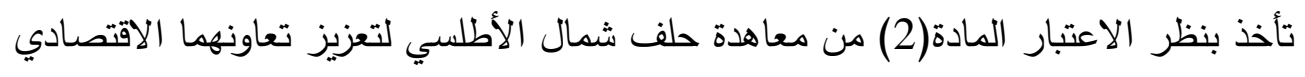

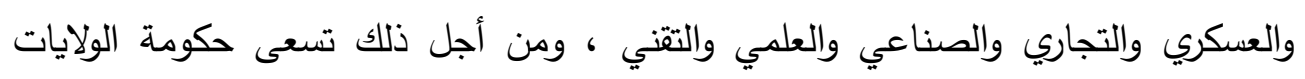


المتحدة الأمريكية من أجل تأمين متطلبات عمليات التتمية في تركيا بالأموال والمسائل التقنية.

المادة (3) من أجل تعزيز تعاونهما الأمني في إطار المادة (3) من معاهدة حلف شمال الأطلسي تؤمن

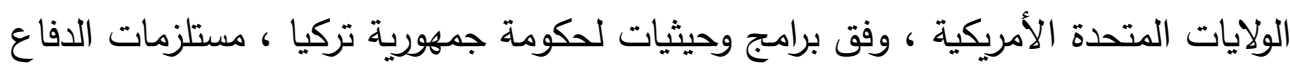
وخدماته وبشتى الوسائل بما ينسجم مع الفترة (1) الخاصة بالدعم العسكري.

المادة (4) (4)

تبحث حكومتا الدولتين المسائل المتعلقة بإنتاج المعدات العسكرية وتسويقها بما ينسجم مع العمان المادة (2) من هذه المعاهدة. وتتحمل الحكومتان تكاليف الإبداعات الخاصة بالتعاون الاقتصادي والعسكري. ولأجل ذلك تقدم حكومة الولايات المتحدة الأمريكية المساعدات اللازمة لحكومة جمهورية

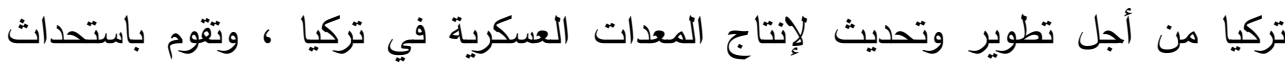
مشاريع جديدة للإنتاج العسكري وتسويقه.

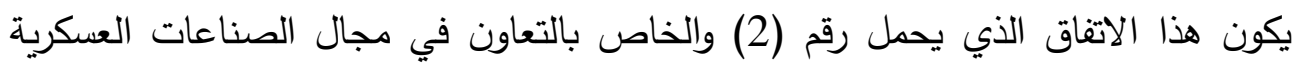
ساري الدفعول في حالة توافقه مع روح المعاهدة.

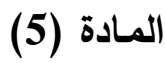

توافق حكومة جمهورية تركيا على اشتراك حكومة الولايات الدتحدة في وضع التدابير الدفاعية المشتركة لمنشآت القوات المسلحة التركية. تتفذ الأنثطة والأعمال الفنية في المنثآت العسكرية وفق برامج وأهداف مشتركة بين الدولتين. لتحقيق أهداف هذه المعاهدة ، تطبق القوات المسلحة والعناصر المدنية الأمريكية المتواجدة

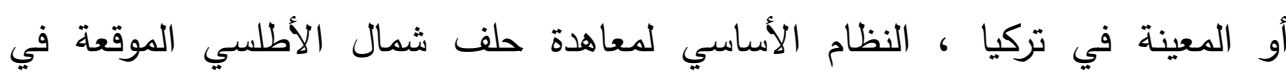
.1959/6/19 إن التعاون العسكري في هذه المعاهدة يثمل المسؤوليات والحدود التي تغرضها معاهدة حلف شمال الأطلسي. 


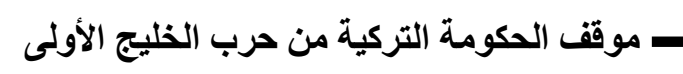

يكون هذا الاتفاق الذي يحمل الرقم (3) والخاص بالتعاون في مجال إقامة المنشآت ساري الأل المفعول في حالة توافقه مع روح المعاهدة.

(6) المادة

يراعى مبدأ المساواة في السيادة عند تطبيق جميع أحكام المعاهدة والأحكام المتممة لها.

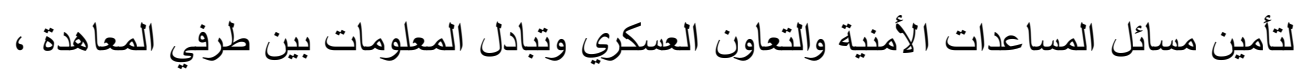
بإمكان الحكومة التركية تعيين ضابط ارتباط في سفارتها بالولايات المتحدة الأمريكية. يمكن للولايات المتحدة الأمريكية ، لضمان تتفيذ أحكام هذه المعاهدة وبالطريقة نفسها الاتصال بالجهات ذات الصلاحية في الحكومة التركية.

(7) المهادة (7)

تتفذ هذه المعاهدة وملحقاتها لخمس سنوات ، وتكون سارية المفعول في حالة عدم مبادرة أي

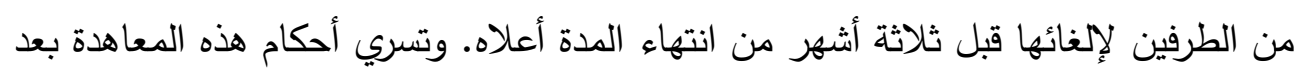
انقضاء هذه المدة لمدة سنة واحدة قابلة للتجديد في حالة عدم وجود الرغبة لدى الطرفين لإلغائها ، وعند الضرورة يقدم الطرف الراغب بالإلغاء إشعارا للطرف الآخر قبل ثلاثة أشهر

من انتهاء السنة.

يتشاور الطرفان فورا لوضع الحلول اللازمة عند تعرض بنود المعاهدة وملحقاتها لأي مشكلة عند تتفيذ بنودها. يبادر الطرفان إلى التشاور فورا في حالة شعور أي من الحكومتين وجود ضرورة لإجراء تعديل أو إيجاد تفسير لبنود المعاهدة وملحقاتها ، وفي حالة عدم التوصل إلى النى النتيجة اللازمة خلال ثلاثة أشهر فإن بإمكان أحد طرفي المعاهدة وخلال فترة (30) يوما تحرير مذكرة يعلم فيها الطرف الآخر بانتهاء المعاهدة. في حالة عدم انسجام أي من الطرفين مع أحكام المعاهدة وملحقاتها يبادر إلى التشاور فورا مع الطرف الآخر. وعند التوصل إلى حل ملائم خلال (30) يوما ، يقدم الطرف المعني مذكرة خلال فترة (30) يوما يعلم فيها الطرف الآخر بانتهاء المعاهدة.

المـادة (8) تسري أحكام هذه المعاهدة وملحقاتها من تاريخ تأييدها من قبل الطرفين. 
داد هلى محمود محمد على نايل

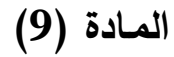

كتبت هذه المعاهدة بالنسختين التركية والإنكليزية بأنقرة في 1980/3/29.

المصدر:

Armaoglu, Fahir, Belgelerle Turk-AmerikanMunasebetleri (Ankara,1991), SS. 300-316.

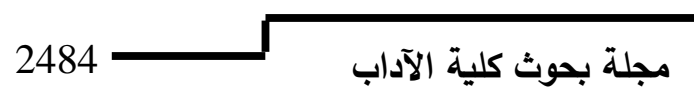

